\title{
Evolution and Development of Effective Feedstock Specifications
}

Garold Gresham

Rachel Emerson

Amber Hoover

Amber Miller

Kevin Kenney

William Bauer

September 2013

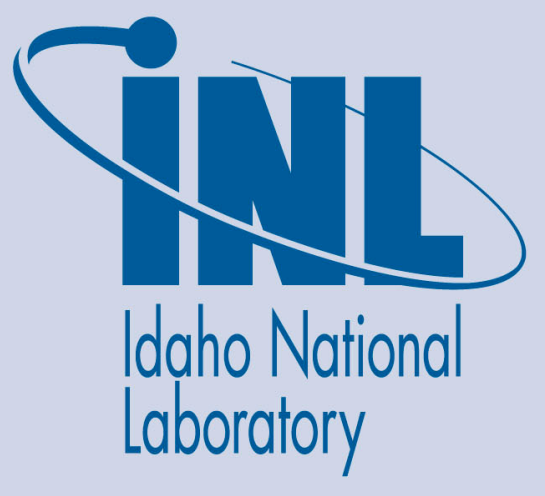

The INL is a U.S. Department of Energy National Laboratory operated by Battelle Energy Alliance 


\section{DISCLAIMER}

This information was prepared as an account of work sponsored by an agency of the U.S. Government. Neither the U.S. Government nor any agency thereof, nor any of their employees, makes any warranty, expressed or implied, or assumes any legal liability or responsibility for the accuracy, completeness, or usefulness, of any information, apparatus, product, or process disclosed, or represents that its use would not infringe privately owned rights. References herein to any specific commercial product, process, or service by trade name, trade mark, manufacturer, or otherwise, does not necessarily constitute or imply its endorsement, recommendation, or favoring by the U.S. Government or any agency thereof. The views and opinions of authors expressed herein do not necessarily state or reflect those of the U.S. Government or any agency thereof. 


\title{
Evolution and Development of Effective Feedstock Specifications
}

\author{
Garold Gresham \\ Rachel Emerson \\ Amber Hoover \\ Amber Miller \\ Kevin Kenney \\ William Bauer
}

September 2013

Idaho National Laboratory Idaho Falls, Idaho 83415

http://www.inl.gov

\author{
Prepared for the \\ U.S. Department of Energy \\ Office of Nuclear Energy \\ Under DOE Idaho Operations Office \\ Contract DE-AC07-05ID14517
}




\begin{tabular}{|l|l|}
\hline $\begin{array}{l}\text { ID\#: 2.1.1.1.A.ML.3 } \\
\text { Type: D } \\
\text { WBS \#: }\end{array}$ & $\begin{array}{l}\text { Completion Date: September 30, 2013 } \\
\text { Scheduled Completion: September 30, 2013 } \\
\text { Platform Area: }\end{array}$ \\
\hline Milestone Title: & Evolution and Development of Effective Feedstock Specifications \\
\hline Authors: & $\begin{array}{l}\text { Garold Gresham, Rachel Emerson, Amber Hoover, Amber Miller, Kevin } \\
\text { Kenney }\end{array}$ \\
\hline $\begin{array}{l}\text { Project Name: } \\
\text { Project Leader: }\end{array}$ & $\begin{array}{l}\text { Biochem Interface Program 2.1.1.1 } \\
\text { Garold Gresham }\end{array}$ \\
\hline Key Words: & Feedstocks, Quality, Specifications \\
\hline
\end{tabular}

\section{EXECUTIVE SUMMARY}

The U.S. Department of Energy promotes the production of a range of liquid fuels and fuel blend stocks from lignocellulosic biomass feedstocks by funding fundamental and applied research that advances the state of technology in biomass collection, conversion, and sustainability. As part of its involvement in this program, the Idaho National Laboratory (INL) investigates the feedstock logistics economics and sustainability of these fuels.

The 2012 feedstock logistics milestone demonstrated that for high-yield areas that minimize the transportation distances of a low-density, unstable biomass, we could achieve a delivered cost of $\$ 35 /$ ton. Based on current conventional equipment and processes, the 2012 logistics design is able to deliver the volume of biomass needed to fulfill the 2012 Renewable Fuel Standard's targets for ethanol. However, the Renewable Fuel Standard's volume targets are continuing to increase and are expected to peak in 2022 at 36 billion gallons. Meeting these volume targets and achieving a national-scale biofuels industry will require expansion of production capacity beyond the 2012 Conventional Feedstock Supply Design Case to access diverse available feedstocks, regardless of their inherent ability to meet preliminary biorefinery quality feedstock specifications. Implementation of quality specifications (specs), as outlined in the 2017 Design Case - "Feedstock Supply System Design and Economics for Conversion of Lignocellulosic Biomass to Hydrocarbon Fuels" (in progress), requires insertion of deliberate, active quality controls into the feedstock supply chain, whereas the 2012 Conventional Design only utilizes passive quality controls.

The three primary requirements that distinguish the 2012 Conventional Design from the 2017 Design Case are that the latter incorporates (1) adherence to biorefinery quality specifications, (2) expansion beyond highly productive resource areas, and (3) moving from a single feedstock to blended feedstocks. The development of definitive feedstock quality specifications is vital to this effort. Development of specifications is challenging due to the variety of possible biomass materials available, variability within the biomass resource, multiple specification drivers or standpoints, evolving logistical design options (as exemplified in the differences between the 2012 and 2017 designs), immaturity of demonstrated conversion refineries, and lack of robust quality characteristics for specific feedstock resources. 
This report describes the influence of intrinsic (compositional and physical biomass characteristics), performance (conversion "performance" targets and infrastructure requirement), and secondary (regulatory requirements) drivers on the development of feedstock specifications. This report reviewed the established industry standards and specifications, and then proceeded to examine the methodology and architecture needed to create and support a specification (spec) approach for biomass feedstock materials, including the following:

- Inherent or performance feedstock quality characteristics for inclusion as a specification

- Integration of preliminary and intermediate specifications that sustain the final conversion specifications

- Selection of the appropriate analytical measurement technique to measure the specification

- Incorporation of unambiguous sampling protocols to ensure that feedstock quality specifications are accurate and representative of the biomass materials tested

- Incorporation of quality assurance procedures to ensure that feedstock quality specifications are accurate and measurement uncertainty is minimized

- Incorporation of general classification and terminology to ensure that suppliers and end-users employ unambiguous and definitive descriptions of the feedstock and feedstock specifications.

Finally, the report reviews four biomass feedstocks; corn stover, switchgrass, Miscanthus, and sorghum. Compositional analysis information through a number of resources: Idaho National Laboratory Biomass R\&D Resource Library, National Renewable Energy Laboratory (NREL) Biomass Feedstock Composition and Property Database, Energy Research Centre of the Netherlands (ECN) Phyllis2 Database for Biomass and Waste, and Peer Reviewed Literature Search were reviewed and compiled to establish practical initial quality attributes for development of feedstock specifications. An attempt was made to determine for each source whether the feedstock was field (commercially) harvested or if it was research grade (not mechanically harvested). 


\section{Purpose and Scope}

\section{Introduction}

The 2012 feedstock logistics milestone demonstrated that for high-yield areas that minimize the transportation distances of a low-density, unstable biomass, we could achieve a delivered cost of $\$ 35 /$ ton. The 2012 logistics design, based on conventional equipment and processes, is able to deliver the volume of biomass needed to fulfill the 2012 Renewable Fuel Standard's volume targets for ethanol. However, the Renewable Fuel Standard's volume targets continue to increase until they peak in 2022 at 36 billion gallons. Meeting these volume targets and achieving a national-scale biofuels industry will require expansion of production capacity beyond the 2012 Conventional Feedstock Supply Design Case to access diverse available feedstocks, regardless of their inherent ability to meet preliminary biorefinery quality feedstock specifications. Implementation of quality specifications (specs), as outlined in the 2017 Design Case - "Feedstock Supply System Design and Economics for Conversion of Lignocellulosic Biomass to Hydrocarbon Fuels" (in progress), requires insertion of deliberate, active quality controls into the feedstock supply chain, whereas the 2012 Conventional Design only utilizes passive quality controls. The three primary requirements that distinguish the 2012 Conventional Design from the 2017 Design Case are that the latter incorporates (1) adherence to biorefinery quality specifications, (2) expansion beyond highly productive resource areas, and (3) moving from a single feedstock to blended feedstocks.

Additionally, the concept of dockage fee is introduced in the 2017 Design Case. Dockage involves the biorefinery penalizing the feedstock supplier for delivery of off-spec feedstock. The dockage fee is established based on the additional cost the biorefinery incurs to process off-spec feedstock; the dockage fee is subtracted from the feedstock payment. If the pre-delivery cost of mitigating off-spec feedstock by the feedstock supplier exceeds the dockage fee, the dockage fee will be accepted; otherwise, the feedstock supplier must implement corrective strategies to avoid the dockage penalty and remain economically competitive. For example, if ash removal is required to meet the biorefinery feedstock quality specification and mitigation within the feedstock supply chain costs the supplier $\$ 15 /$ ton, but the biorefinery is able to mitigate the ash for $\$ 10 /$ ton, the feedstock supplier may choose to accept the $\$ 10 /$ ton dockage fee rather than implement ash reduction, for a net $\$ 5 /$ ton savings.

The requirements and the dockage concept are discussed in detail in the 2017 Design Case. Feedstock logistics research aims to reduce delivered cost, improve or preserve feedstock quality, and expand feedstock access. Strategies to improve logistics operations include (1) organizing logistics in innovative ways, (2) improving existing operations for efficiency and interaction with other operations, and (3) implementing new technologies to overcome quality issues. The development of definitive feedstock quality specifications is vital to this effort. Development of specifications is challenging due to the variety of possible biomass materials available, variability within the biomass resource, multiple specification drivers or standpoints, evolving logistical design options (as exemplified in the differences between the 2012 and 2017 designs), and, most importantly, immaturity of the demonstrated conversion refinery. This document will primarily focus on the development of intrinsic quality specifications, the many factors that influence the approach and evolution of specifications, and the architecture needed to support a specification approach. 


\section{$\underline{\text { Key Results }}$}

\section{$\underline{\text { Spec Development and Evolution }}$}

The evolution and development of biomass feedstock quality specifications are challenging given that they can be driven from multiple drivers or standpoints (i.e., development of a specification builds upon the intrinsic compositional and physical characteristics of the biomass feedstock or the performance targets established by the needs and requirements of the refinery process and equipment). The performance-driven targets are determined based on the requirements of the biomass refinery to meet conversion "performance" targets and limitations of the system infrastructure (e.g., system requirements for flowability, minimization of catalysts contamination, etc.). Intrinsic specifications are base on the inherent characteristics of the feedstock material itself and may include moisture, ash, hemicellulose, cellulose, elemental and lignin content [1], in addition to physical characteristics (i.e., grind size, particle size distribution, fines content, flowability, and durability). Specifications are also influenced by a secondary driver, which may include legal requirements that limit the spread of insect infestations, state or regional limitations on the import of specific feedstock types that may be deemed invasive plant species, or the cost to achieve and maintain the specification. The scope of this document is primarily focused on investigating the underlying architecture that needs to be addressed to support feedstock specifications for the bioenergy industry and the development of initial intrinsic feedstock specifications developed through the quality characteristic of the biomass feedstock materials. Prospective feedstock specifications will be driven by refinery performance targets, intrinsic quality characteristics, and secondary drivers (see Figure 1). As intrinsic and performance drivers mature, resulting specifications will become more defined, have less variability, and become more succinct. Future efforts will continue to clarify the fundamental intrinsic characteristics and identify essential performance parameters that become dominant for the biofuels industry. Most importantly, specifications must be readily and easily measured with good accuracy and precision to effectually impact conversion performance; if the specification cannot be readily and easily measured with good accuracy and precision, the specification is of no value. 


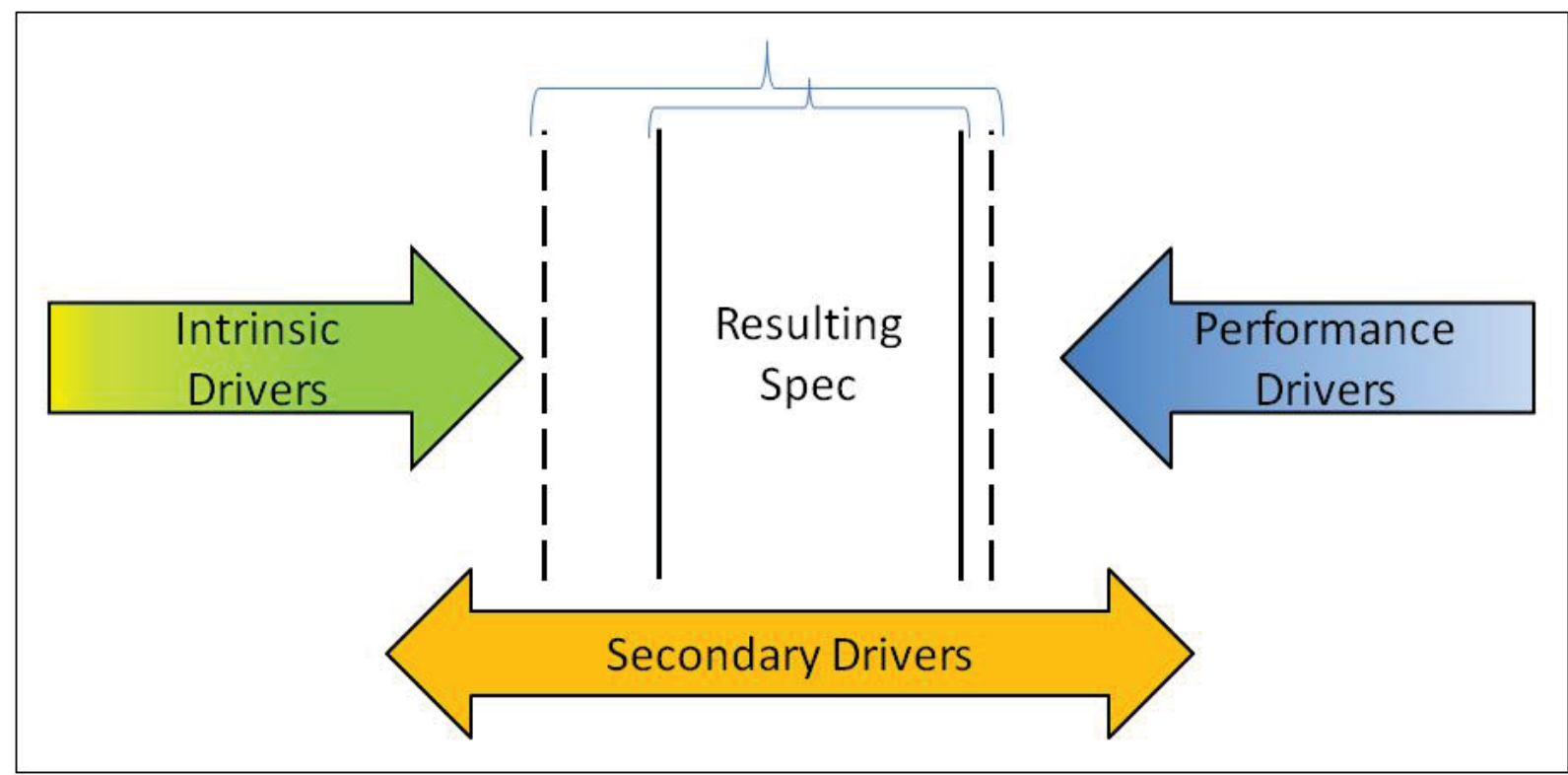

Figure 1. Evolution of potential specifications driven by intrinsic feedstock characteristics, secondary drivers, and performance targets; as intrinsic and performance drivers mature, resulting specifications will become more defined (less variable).

\section{$\underline{\text { Industry Standards and Specifications }}$}

When reviewing the biofuels and feedstock supply industry, there are few examples of established specifications (specs) for feedstock materials, especially those driven by performance requirements. We can look to the U.S. Department of Agriculture or the European Commission, in which "standards are based on measurable attributes that describe the value and utility of the product"

(http://www.gipsa.usda.gov/fgis/standproc/usstands). In this case, a "standard" can be described as a level of quality or attainment and is accepted as the normal or average for the overall commodity system. The purpose of this document is not the development of an overall system or commodity standard, but many of the same aspects and supporting features that are used to define and maintain a standard are applicable to specifications as well.

\section{U.S. Department of Agriculture Grain Standard}

The Grain Standard, for example, includes 12 grains (e.g., corn, flax seed, sorghum, and other grains), rice, peas, lentils, and beans and is described in the General Provision 810, U.S. Standards for Grain [2]. The specific Standard for Wheat [3] establishes the classes for wheat (i.e., durum wheat, hard red spring wheat, hard red winter wheat, soft red winter wheat, hard white wheat, soft white wheat, unclassed wheat, and mixed wheat), multiple grades, and grade requirements. There are five grades (1 through 5) that incorporate several grading factors, as seen in Table 1. 
Table 1. Grades and grade requirements for all classes of wheat, except mixed wheat [3].

\begin{tabular}{|c|c|c|c|c|c|}
\hline \multirow[t]{2}{*}{ Grading factors } & \multicolumn{5}{|c|}{ Grades U.S. Nos. } \\
\hline & 1 & 2 & 3 & 4 & 5 \\
\hline \multicolumn{6}{|c|}{ Minimum pound limits of: } \\
\hline $\begin{array}{l}\text { Test weight per bushel } \\
\text { Hard red spring wheat or white club wheat } \\
\text { All other classes and subclasses }\end{array}$ & $\begin{array}{c}58.0 \\
60.0\end{array}$ & $\begin{array}{l}57.0 \\
58.0\end{array}$ & $\begin{array}{l}55.0 \\
56.0\end{array}$ & $\begin{array}{l}53.0 \\
54.0\end{array}$ & $\begin{array}{l}50.0 \\
51.0\end{array}$ \\
\hline \multicolumn{6}{|l|}{ Maximum percent limits of: } \\
\hline $\begin{array}{l}\text { Defects: } \\
\text { Damaged kernels } \\
\text { Heat (part of total) } \\
\text { Total } \\
\text { Foreign material } \\
\text { Shrunken and broken kernels } \\
\quad \text { Total }{ }^{1 /} \\
\text { Wheat of other classes: }{ }^{2 /} \\
\text { Contrasting classes } \\
\text { Total } \\
\text { Stones }\end{array}$ & $\begin{array}{l}0.2 \\
2.0 \\
0.4 \\
3.0 \\
3.0\end{array}$ & $\begin{array}{l}0.2 \\
4.0 \\
0.7 \\
5.0 \\
5.0 \\
2.0 \\
5.0 \\
0.1\end{array}$ & $\begin{array}{l}0.5 \\
7.0 \\
1.3 \\
8.0 \\
8.0\end{array}$ & $\begin{array}{c}1.0 \\
10.0 \\
3.0 \\
12.0 \\
12.0 \\
10.0 \\
10.0 \\
0.1\end{array}$ & $\begin{array}{c}3.0 \\
15.0 \\
5.0 \\
20.0 \\
20.0\end{array}$ \\
\hline \multicolumn{6}{|c|}{ Maximum count limits of: } \\
\hline $\begin{array}{l}\text { Other material in one kilogram: } \\
\text { Animal filth } \\
\text { Castor beans } \\
\text { Crotalaria seeds } \\
\text { Glass } \\
\text { Stones } \\
\text { Unknown foreign substances } \\
\quad \text { Total } \\
\text { Insect-damaged kernels in } 100 \text { grams }\end{array}$ & $\begin{array}{c}1 \\
1 \\
2 \\
0 \\
3 \\
3 \\
4 \\
31\end{array}$ & $\begin{array}{c}1 \\
1 \\
2 \\
0 \\
3 \\
3 \\
4 \\
31\end{array}$ & $\begin{array}{c}1 \\
1 \\
2 \\
0 \\
3 \\
3 \\
4 \\
31\end{array}$ & $\begin{array}{c}1 \\
1 \\
2 \\
0 \\
3 \\
3 \\
4 \\
31\end{array}$ & $\begin{array}{c}1 \\
1 \\
2 \\
0 \\
3 \\
3 \\
4 \\
31\end{array}$ \\
\hline \multicolumn{6}{|c|}{$\begin{array}{l}\text { U.S. sample grade is wheat that: } \\
\text { (a) Does not meet the requirements for U.S. Nos. 1, 2, 3, 4, or } 5 \\
\text { (b) Has a musty, sour, or commercially objectionable foreign odor (except smut or garlic odor) } \\
\text { (c) Is heating or of distinctly low quality. }\end{array}$} \\
\hline
\end{tabular}

It is important to note that the overall composition of wheat for the various grades is not included in the standard; this is consistent with the European Committee for Standardization (CEN)/TC 355, "Solid Biofuel," discussed below. The focus of the standard is on the outward visual characteristics of wheat, bulk density, defects, and contamination; however, the standard does present the language for wheat exchange, providing an unambiguous and definitive description of the commodity so that producers and 
buyers know what to expect for a specific grade of wheat. Deliverable grades for wheat do include protein content, as seen in the Minneapolis Grain Exchange [5]. Additionally, protein, falling number (Hagberg), and single kernel characterization are optional, non-grade-determining tests that may be required by the customer. The value of the standards, grades, and specifications is that they establish the language for suppliers, exchange points, and end users, so that throughout the supply chain, each intermediary has an unambiguous and definitive understanding of the commodity. The incorporation of explicit terminology and language is vital and is directly applicable to biomass feedstock specifications for a given feedstock resource, supplier, conversion technology, and biorefinery.

\section{European Union Solid Biofuel Standard}

The CEN has established standards for biomass resources, including wood chips, wood pellets and briquettes, logs, sawdust, and straw bales under CEN/TC 355, "Solid Biofuel." The standards include several standard references that describe all forms of solid biofuels within the European Union. The CEN/TC 355 standard describes the relevant properties of the biofuels, physical and chemical properties of the fuel, and provides information on the source of the material, consistent with the Grain Standard (i.e., woody biomass (1); forest, plantation, and other virgin wood (1.1); whole tree without roots (1.1.1); and short rotation coppice (1.1.1.3)). Again, it is important to note that the overall composition is not explicitly determined; however, the chemical composition relevant to a 'Solid Biofuel' is assumed based on the source or resource. The purpose of the CEN/TC 355 standard is to ensure that the biomass feedstock material is eminently usable from one batch to the next and that the feedstock can be used in a particular piece of equipment and operate according to specification.

The CEN has developed EN 14961-1, "Solid Biofuel - Fuel Specifications and Classes," that standardizes solid biomass fuels for energy generation. The EN 14961-1 standard provides the methods to describe the physical and chemical characteristics of the fuel, as well as information on the material's source. CEN/TC 355 establishes general classification, terminology (EN 14588:2010), material dimensions, sampling and preparation procedure, testing and analysis standards, and quality assurance procedures (CEN/TR 15569:2009). Separate product standards have been created for wood chips and hog fuel (EN 14961-1), wood pellets (EN 14961-2), wood briquettes (EN 14961-3), wood chips for non-industrial use (EN 14961- 4), firewood (EN 14961-5), and non-woody pellets (EN 14961-6). Currently, there are more than $30 \mathrm{CEN}$ standards specific to solid biofuels. Of specific importance for this discussion are the fuel quality specifications for solid biofuels, which includes moisture content; ash content; bulk density; particle density; ash melting behavior; mechanical durability; net calorific value; total content of carbon, hydrogen, and nitrogen; volatile content; water soluble chloride; sodium and potassium content; and particle size distribution, with pending or postponed standards for bridging properties and impurities, respectively. Some properties are normative (mandatory), while other properties are informative (voluntary); the normative properties are as follows:

- Origin and source

- Moisture content

- Ash content

- Other normative properties vary depending on both origin and traded form.

Overall the specifications have been created to establish descriptions and definitions, how different parameters are determined, and how fuel quality is monitored and maintained through the supply chain. The standard reference and title for the selected technical standards are listed in Table 2. 
The EN 14961standard provides instructions on how to state the fuel quality by product declaration. The product declaration is issued by the supplier. An example of a product declaration for woodchips is seen in Table 3, and it simply describes the quality of the product in accordance to the appropriate part of the EN 14961 standard. Using the appropriate standard, the normative and informative properties were established.

\section{Commercial Proprietary Blend}

Specifications developed by private industry are often proprietary or not well developed; other refineries openly state that they "tune their processes to the characteristics of the feedstock materials" (Department of Energy Peer Review 2013, IBR Overview, MAS10BIO5, Mascoma, Michael Ladisch). However, Koda Energy has developed a specific blend of feedstock materials designed to maintain consistent heat output and limit emissions for their Minneapolis-St. Paul, Minnesota combined heat and power (CHP) plant [6]. Fundamental specifications, as well as segregation specifications, have been developed for the propriety blending of the feedstock materials for the CHP facility. Feedstock resources include malting residues, whole tree, oat hulls, corn cobs, aged seed corn, undersized whole grain products, sunflower seed materials, pallet woods, and other dried agronomic materials. The specifications include grind size and moisture content; feedstock materials are segregated by material type, ash content, Btu value, and alkali content per million Btu (i.e., segregation specifications) at the CHP plant. The initial grind size is driven by two separate requirements: the first is to meet wood quarantine requirements (i.e., reducing the size of the wood materials to the point that the emerald ash borer cannot survive) and the other is logistical (i.e., increasing the hauling capacity from 10 tons to 24 tons per 100-cubic yard semitrailer). Chippers and single pass driers are used to achieve the final fuel specification of 3/4-in. grind size and less than $14 \%$ moisture content. Satellite biomass preparation facilities (consistent with the depot concept) are utilized for initial receipt of the biomass materials and initial sizing. Feedstocks are blended at the CHP plant to a specific ratio to meet the plant combustion needs; the specific ratio in itself can be considered a final conversion specification. 
Table 2. CEN TC 355 published technical standards.

\begin{tabular}{|c|c|c|c|}
\hline $\begin{array}{l}\text { Standard } \\
\text { Reference }\end{array}$ & Property Class & Property & Title \\
\hline EN 14774-1:2009 & Normative & $\%$ Moisture & $\begin{array}{l}\text { Solid biofuels - Determination of moisture content - } \\
\text { Oven dry method. Total moisture: Reference method }\end{array}$ \\
\hline EN 14774-2:2009 & Normative & $\%$ Moisture & $\begin{array}{l}\text { Solid biofuels - Determination of moisture content - } \\
\text { Oven dry method. Total moisture: Simplified method }\end{array}$ \\
\hline EN 14774-3:2009 & Normative & $\%$ Moisture & $\begin{array}{l}\text { Solid biofuels - Determination of moisture content - } \\
\text { Oven dry method. Moisture in general analysis } \\
\text { sample }\end{array}$ \\
\hline EN 14775:2009 & Normative & $\%$ Ash & Solid biofuels - Determination of ash content \\
\hline EN 14918:2009 & Informative & Calorific value & Solid biofuels - Determination of calorific value \\
\hline EN 15103:2009 & Informative & Bulk density & Solid biofuels - Determination of bulk density \\
\hline EN 15104:2011 & $\begin{array}{l}\text { Normative*/ } \\
\text { Informative }\end{array}$ & $\mathrm{C}, \mathrm{H}, \mathrm{N}$ & $\begin{array}{l}\text { Solid biofuels - Determination of total content of } \\
\text { carbon, hydrogen and nitrogen - Instrumental } \\
\text { methods }\end{array}$ \\
\hline EN 15105:2011 & $\begin{array}{l}\text { Normative*/ } \\
\text { Informative }\end{array}$ & $\mathrm{Cl}, \mathrm{Na}, \mathrm{K}$ & $\begin{array}{l}\text { Solid biofuels - Determination of the water soluble } \\
\text { chloride, sodium and potassium content }\end{array}$ \\
\hline EN 15148:2009 & Informative & Volatiles & $\begin{array}{l}\text { Solid biofuels - Determination of the content of } \\
\text { volatile matter }\end{array}$ \\
\hline EN 15149-1:2010 & Normative & Particle size & $\begin{array}{l}\text { Solid biofuels - Determination of particle size } \\
\text { distribution - Part 1: Oscillating screen method using } \\
\text { sieve apertures of } 1 \mathrm{~mm} \text { and above }\end{array}$ \\
\hline EN 15149-2:2010 & Normative & Particle size & $\begin{array}{l}\text { Solid biofuels - Determination of particle size } \\
\text { distribution - Part 2: Vibrating screen method using } \\
\text { sieve apertures of } 3,15 \mathrm{~mm} \text { and below }\end{array}$ \\
\hline EN 15150:2011 & Informative & Particle density & Solid biofuels - Determination of particle density \\
\hline EN 15210-1:2009 & Informative & Durability & $\begin{array}{l}\text { Solid biofuels - Determination of mechanical } \\
\text { durability of pellets and briquettes - Part 1: Pellets }\end{array}$ \\
\hline EN 15210-2:2010 & Informative & Durability & $\begin{array}{l}\text { Solid biofuels - Determination of mechanical } \\
\text { durability of pellets and briquettes - Part 2: Briquettes }\end{array}$ \\
\hline EN 15370:2006 & Informative & Ash behavior & $\begin{array}{l}\text { Solid biofuels - Method for the determination of ash } \\
\text { melting behavior - Part 1: Characteristic temperatures } \\
\text { method }\end{array}$ \\
\hline N 15290:2011 & Informative & Major elements & $\begin{array}{l}\text { Solid biofuels - Determination of major elements - } \\
\mathrm{Al}, \mathrm{Ca}, \mathrm{Fe}, \mathrm{Mg}, \mathrm{P}, \mathrm{K}, \mathrm{Si}, \mathrm{Na} \text { and } \mathrm{Ti}\end{array}$ \\
\hline EN 15297:2011 & Informative & Minor elements & $\begin{array}{l}\text { Solid biofuels - Determination of minor elements - } \\
\mathrm{As}, \mathrm{Cd}, \mathrm{Co}, \mathrm{Cr}, \mathrm{Cu}, \mathrm{Hg}, \mathrm{Mn}, \mathrm{Mo}, \mathrm{Ni}, \mathrm{Pb}, \mathrm{Sb}, \mathrm{V} \text { and } \\
\mathrm{Zn}\end{array}$ \\
\hline
\end{tabular}

*Normative for chemically treated biomass; informative for all fuels that are not chemically treated. 
Table 3. Example of the product declaration for wood chips as defined by EN 14961-1.

\begin{tabular}{|c|c|}
\hline \multicolumn{2}{|l|}{ Product Declaration - Wood Chips } \\
\hline Supplier & $\begin{array}{l}\text { Name } \\
\text { Address }\end{array}$ \\
\hline Quality Assurance Standard & EN 15234-1 \\
\hline Country of Origin & Country \\
\hline Traded Form & Wood chips \\
\hline \multicolumn{2}{|c|}{ Normative Properties - EN 14961-1 } \\
\hline Origin $^{*}$ & $\begin{array}{l}\text { Mixture of stem wood from broadleaf and } \\
\text { coniferous trees }(1.1 .3 .1,1.1 .3 .2)\end{array}$ \\
\hline Particle size ${ }^{* *}, \mathrm{P}, \mathrm{mm}$ & $\mathrm{P} 45 \mathrm{~A}$ \\
\hline Moisture content, M, w-\% $\%$ & M35 \\
\hline Ash content, w- $\%$ of dry matter & A1.5 \\
\hline \multicolumn{2}{|c|}{ Informative Properties - EN 14961-1 } \\
\hline Net calorific value as received, $\mathrm{Q}, \mathrm{MJ} / \mathrm{kg}$ & Q11.5 \\
\hline Bulk density, $\mathrm{BD}, \mathrm{kg} / \mathrm{m}^{3}$ & BD200 \\
\hline Chemical treatment & No \\
\hline
\end{tabular}

\section{Evolution of Specifications}

The examples above provide insight into the methodology and architecture needed to create and support a specification (spec) approach for biomass feedstock materials. For any specification approach to be functional, regardless of the conversion technology, the specification must incorporate the architecture and the methodology to support the final conversion specification and any supporting intermediate specifications. Issues to be considered include the following:

- What inherent or performance feedstock quality characteristics need to be included as a specification? For a particular conversion technology or commercial process the specification class will most likely be different (i.e., $\mathrm{C}, \mathrm{N}, \mathrm{H}, \mathrm{S}, \mathrm{O}$ content is of importance for thermochemical processes, whereas carbohydrate content is most likely of primary importance to biochemical sugars to hydrocarbons processes).

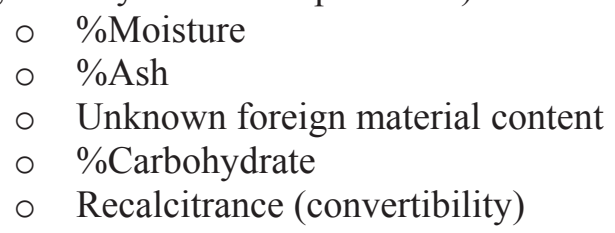


Inhibitor content

○ \%Lignin

- Elemental content (e.g., Cl, P, Ca, Si, and S)

- Grind size

- Particle size distribution

- Flowability

- Insecticide content. ${ }^{1}$

- Integration of preliminary and intermediate specifications that sustain the final conversion specifications, as well as enhance logistical operations.

- Field-side spec

- Format spec

- Exchange-point spec

- Intermediate spec

- Grades

- Final conversion spec.

- Selection of the appropriate analytical measurement technique to measure the specification in the field or exchange point, at the processing depot, and ultimately at the throat of the biorefinery. Cost implications, ease of use, and usability influence the choice of the analytical measurement technique.

$\circ$ Gravimetric techniques

- Spectral approaches

- Semi-quantitative screening techniques

- Full chemical analysis.

- Incorporation of unambiguous sampling protocols to ensure that feedstock quality specifications are accurate and representative of the biomass materials tested. Analytical results are heavily impacted by sampling and sample preparation due to the high variability of the feedstock resource [7].

- Incorporation of standard methods and quality assurance procedures to ensure that feedstock quality specifications are accurate and measurement uncertainty is minimized and to ensure that the biomass feedstock material is eminently usable from one batch to the next.

- Incorporation of general classification and terminology to ensure that suppliers and end users employ unambiguous and definitive descriptions of the feedstock and feedstock specifications.

As stated above, the evolution and development of biomass feedstock specifications is challenging due to the variety of possible biomass materials and formats available, variability within the biomass resource, multiple specification drivers or standpoints, evolving logistical design options, and immaturity of

\footnotetext{
${ }^{1}$ Persistent herbicides in compost caused damage to a variety of garden plants as described in "Unraveling the Maze of Persistent Herbicides in Compost" [Nora Goldstein, "Unraveling the Maze of Persistent Herbicides in Compost," BioCycle Magazine, Oct. 2013, 17-35, Print]
} 
demonstrated conversion refineries. Additionally, the specification approach requires a robust and well-developed administrative infrastructure to be practical, otherwise gaps in the specification architecture will allow the specifications to become ambiguous and ineffectual.

Those feedstock characteristics that most likely will evolve initially into a specification are general in nature and applicable to multiple conversion technologies. A good example of a general feedstock characteristic is grind or particle size (particle size distribution). The Biomass Feedstock Process Demonstration Unit routinely produces bulk quantities of feedstock materials for end users at multiple grind sizes, typically $1 / 2$ to 2 -in. screen size grinds. The particle size distribution (including fines content) is a concern for specific end users and can be readily controlled using specific screen sizes in combination with specific grinders or fractional milling. Fractional milling's logistical design incorporates a separations step between the first and second-stage grinding operations to remove material that already meets the size specification and only passes the oversized material on for further size reduction, as discussed the 2017 Design Case [7]. Attributes (such as grind size, which is relatively easily controlled through logistical preprocessing) can readily be developed into a specification. The specification can be as simple as follows:

$$
\begin{aligned}
& \leq 1 / 2 \text {-in. grind using a Bliss hammer mill } \\
& \leq 3 / 4 \text {-in. grind using a Bliss hammer mill } \\
& \leq 1 \text {-in. grind using a Bliss hammer mill. }
\end{aligned}
$$

Or it can progress to a more detailed particle specification as developed in EN 14961-1, where minimum fines and coarse fractions are explicitly defined as seen in Table 4.

The evolution of a specification will also be directly influenced by the cost, level of effort, and difficulty to maintain the specification. The maintenance of a specification expressly deals with the complexity of the specification's requirements, including the specificity (precision and detail) of the specification, the overall ease of determining the specification, analytical methodology, and sampling requirements. Most importantly, can the needed specification be readily and easily measured with good accuracy and precision to effectually impact the conversion performance? If it cannot, the specification is of little or no value.

Feedstock ash content, for example, represents an additional, variable, operational cost to the biological conversion refinery because it reduces pretreatment efficacy [8], increases wear in handling and feeding systems, increases water treatment cost, and accumulates as a waste stream that requires treatment.

Bonner et al. [7] estimated the cost of biomass ash above and beyond a 5\% feedstock specification for a sugars/fermentation pathway to ethanol, considering both the additional replacement costs and additional disposal costs. Their analysis showed that these costs ranged from $\$ 4.88$ to $\$ 20.23 /$ dry $\mathrm{T}$ for corn stover ash levels, ranging from 10 to $25 \%$, respectively. Two-thirds of the cost increase was due to feedstock replacement costs (carbohydrate content) to maintain the required supply of convertible biomass to the biorefinery, and one-third of the increase was due to the biorefinery's ash disposal costs. Therefore, the inclusion of an ash specification (\%Ash) for biological conversion of sugars to hydrocarbons is appropriate. 
Table 4. Particle size specification for wood chips [EN 14961-1].

\begin{tabular}{|c|c|c|c|}
\hline \multicolumn{4}{|c|}{ Particle Size - Wood Chips } \\
\hline \multicolumn{4}{|c|}{ Property Class: Normative } \\
\hline \multicolumn{4}{|c|}{ Standard Reference: EN 14961-1 } \\
\hline Class & $\begin{array}{l}\text { Minimum } 75-w \% \text { in } \\
\text { Main Fraction, } \mathbf{m m}^{\mathrm{a}}\end{array}$ & $\begin{array}{l}\text { Fines Fraction, } \\
\mathrm{w}-\%(<3,15 \mathrm{~mm})\end{array}$ & Coarse Fraction, w- $\%$ \\
\hline P16A & $3.15 \leq \mathrm{P} \leq 16 \mathrm{~mm}$ & $\leq 12 \%$ & $\leq 3 \%>16 \mathrm{~mm}$ and all $30 \mathrm{~mm}^{\mathrm{c}}$ \\
\hline P16 B & $3.15 \leq \mathrm{P} \leq 16 \mathrm{~mm}$ & $\leq 12 \%$ & $\leq 3 \%>45 \mathrm{~mm}$ and all $120 \mathrm{~mm}^{\mathrm{c}}$ \\
\hline P45A & $8 \leq \mathrm{P} \leq 45 \mathrm{~mm}$ & $<8 \%^{b}$ & $\begin{array}{l}\leq 6 \%>63 \mathrm{~mm}, \text { and } \max .3,5 \\
\%>100 \mathrm{~mm}, \text { all }<120 \mathrm{~mm}\end{array}$ \\
\hline P45B & $8<\mathrm{P}<45 \mathrm{~mm}$ & $<8 \%^{b}$ & $\begin{array}{l}\leq 6 \%>63 \mathrm{~mm}, \text { and } \max .3,5 \\
\%>100 \mathrm{~mm} \text { all }<350 \mathrm{~mm}\end{array}$ \\
\hline P63 & $8<\mathrm{P}<63 \mathrm{~mm}$ & $<6 \%^{\mathrm{b}}$ & $\leq 6 \%>100 \mathrm{~mm}$, and all $<350 \mathrm{~mm}$ \\
\hline P100 & $16<\mathrm{P}<100 \mathrm{~mm}$ & $<4 \%{ }^{\mathrm{b}}$ & $<6 \%>200 \mathrm{~mm}$, and all $<350 \mathrm{~mm}$ \\
\hline \multicolumn{4}{|c|}{$\begin{array}{l}{ }^{\mathrm{a}} \text { The numerical values (P-class) for dimension refer to the particle sizes passing through the mentioned round hole sieve size } \\
\text { according to standard EN } 15149-1 \text {. } \\
{ }^{\mathrm{b}} \text { Main fraction for P45B is } 3.15<\mathrm{P}<45 \mathrm{~mm} \text {, for P63 is } 3.15<\mathrm{P}<63 \mathrm{~mm} \text {, and for P100 is } 3.15<\mathrm{P}<100 \mathrm{~mm} \text {, and the amount } \\
\text { of fines can be a maximum } 25 \mathrm{w}-\% \text { if raw material is logging residue, which includes thin particles like branches, needles, or } \\
\text { leaves. } \\
{ }^{\mathrm{c}} \text { The cross-sectional area of the oversized particles shall be } \mathrm{P} 16<1 \mathrm{~cm}^{2} \text {, for } \mathrm{P} 45<5 \mathrm{~cm}^{2} \text {, for P } 63<10 \\
\mathrm{~cm}^{2} \text {, and P100 }<10 \mathrm{~cm}^{2} \text {. }\end{array}$} \\
\hline
\end{tabular}

Unfortunately, ash content can vary greatly. Table 5 shows the mean and range of ash contents for selected feedstocks and includes the effects of physiological ash (ash inherent in the biomass) and soil contamination. Research to-date has shown herbaceous feedstock ash content to be highly dependent on harvest equipment [9]. Traditional multi-pass corn stover bales from Stevens County, Kansas, were found to range from 10 to $25 \%$ ash by mass [7]. An additional complication of establishing an ash spec is the high spatial variability of ash within a bale. Bonner et al. [7] made this important conclusion from the Stevens County, Kansas field study, where the location of ash in the corn stover bales did not appear to follow any significant pattern, supporting the need for random sampling and compositing to obtain representative bulk ash content. For a 160-acre "quarter section" field, the research supports taking three randomly collected cores samples and compositing from each truckload of baled biomass, with an estimated 11 trucks total. The eleven measured ash values are then averaged to calculate a single mean bulk ash content for the field at a $95 \%$ confidence interval of $1.5 \%$ (this is assuming no analytical error in the ash measurement). Establishing \%Ash specifications for baled corn stover and herbaceous material similar to the grades established in the EN 14961-1 woody ash content standard $\leq 0.5 \%, \leq 0.7 \%, \leq 1.0 \%$, $\leq 1.5 \%, \leq 3.0 \%, \leq 5.0 \%, \leq 7.0 \%, \leq 10.0 \%$, and $>10.0 \%$ is not viable because the sampling error at the $95 \%$ confidence interval is greater than the initial $0.2 \%$ grade interval (interval for $0.5 \%$ and $0.7 \%$ ) cited. The analytical error for the gravimetric determination of ash is less than $0.15 \%$ relative standard deviations (RSD), is achievable for a uniform sample (INL Biomass Characterization Laboratory, Reported RSD's for NIST Reference Material 8491 Sugarcane Bagasse \%Ash: ASTM Standard Test Method D3174-04), and is well below the sampling error observed; therefore, the most crucial aspect of determining the ash content and specifying an ash spec is obtaining representative samples. 
Table 5. Mean total ash values and ranges for selected lignocellulosic biomass feedstocks [9].

\begin{tabular}{l|c|c}
\hline Feedstock & Average Ash (\%)* & Reported Range (\%) \\
\hline Corn Cob & $2.9(13)$ & $1.0-8.8$ \\
\hline Corn Stover & $6.6(28)$ & $2.9-11.4$ \\
\hline Miscanthus Straw & $3.3(13)$ & $1.1-9.3$ \\
\hline Reed Canary Grass & $6.7(11)$ & $3.0-9.2$ \\
\hline Rice Straw & $17.5(22)$ & $7.6-25.5$ \\
\hline Sorghum Straw & $6.6(5)$ & $4.7-8.7$ \\
\hline Sugarcane Bagasse & $5.6(27)$ & $1.0-15.2$ \\
\hline Switchgrass Straw & $5.8(21)$ & $2.7-10.6$ \\
\hline Wheat Straw & $8.0(50)$ & $3.5-22.8$ \\
\hline
\end{tabular}

* Mean value presented with number of reported samples in parenthesis.

Consistent and predictable conversion of cellulosic biomass to fuels by a biochemical conversion facility requires that the feedstock's structural carbohydrates are delivered at a known quantity and quality. The assumed feedstock specifications shown in Table 6 indicate that a minimum 59\% total structural carbohydrate content is required for the biorefinery to meet the conversion yield targets. In developing a $\%$ Carbohydrate spec, an important question is at what point within the logistical process does the determination of carbohydrate content provide benefit? As seen in Figure 2, there are several locations within the logistical process where measurement of carbohydrate content may be appropriate; however, at what point is a measurement (corresponding specification) cost effective and does an initial measurement effectually impact the conversion performance. One approach, consistent with the sourcing of woody materials in the Standard for Wheat and EN 14961 Standard, used the ash content (\%ash) as the exchange-point specification and assumes that the carbohydrate content is consistent with typical regional or supplier (source) composition. That is, for a typical multi-pass harvested corn stover (see Table 7), the $\%$ Carbohydrate and \%Ash are assumed to $58 \%$ and $7 \%$, respectively; as ash content increases or decreases, the carbohydrate content decreases or increases correspondingly. This removes the burden and cost of determining carbohydrate content in field applications. Measurement of carbohydrate content is needed as the feedstock moves through the logistical chain and undergoes preprocessing, chemical preconversion, and formulation or blending (modification of carbohydrate content and ash content) to meet the final refinery specifications. At the points within the logistical process where the carbohydrate content is still variable and quality cannot be controlled, \%carbohydrate monitoring is justified.

Table 6. Delivered corn stover composition assumptions [10].

\begin{tabular}{lc}
\hline Component & $\begin{array}{c}\text { Composition } \\
\text { (dry wt\%) }\end{array}$ \\
\hline Glucan & 35.05 \\
Xylan & 19.53 \\
Lignin & 15.76
\end{tabular}




\begin{tabular}{lc} 
Ash $^{\mathrm{a}}$ & 4.93 \\
Acetate $^{\mathrm{b}}$ & 1.81 \\
Protein & 3.10 \\
Extractives & 14.65 \\
Arabinan & 2.38 \\
Galactan & 1.43 \\
Mannan & 0.60 \\
Sucrose & 0.77 \\
Total structural carbohydrate & 58.99 \\
Total structural carbohydrate + sucrose & 59.76 \\
Moisture (bulk wt\%) & 20.0 \\
\hline${ }^{\mathrm{a}}$ Future studies will break down ash constituency. & \\
${ }^{\mathbf{b}}$ Represents acetyl groups present in the hemicellulose polymer converted to \\
acetic acid in pretreatment.
\end{tabular}

Regrettably, the determination of carbohydrate content is not as simple and straight forward as the gravimetric determination of ash content. Conventional analytical methods ${ }^{2}$ for the characterization of feedstock materials require transfer of samples to an analytical laboratory; analysis is both costly and time intensive. Multiply that by several hundred samples per logistical operation and then again by many harvest resources; this results in a significant number of samples that well exceed most feedstock resource budgets for characterization. A rapid compositional analysis method using near-infrared spectroscopy/partial least squares multivariate modeling (NIR/PLS) [12, 13] provides the opportunity to rapidly evaluate the chemical composition of feedstock intermediates during preprocessing. Unfortunately, the methodology has not been readily adapted to field-measurements or preprocessing operations, but is routinely used for quality control in the food [14], beverage [15], cosmetics [16], pharmaceutical [17], and feed and forage testing industries [18], and is routinely used for the rapid characterization of biomass feedstock materials in the laboratory [12],[13]. Combined standard deviations of less than $8 \%$ are anticipated for online processing [19]. An RSD of 1.3 to 5.7\% for crude protein and $\mathrm{ADF}$ and NDF measurements [18] have been demonstrated for feed and forage testing. When good laboratory methods are followed, RSDs improve (1.3 to 1.7\%). Additional insight is provided by examining the raw and corrected spectra of 91 individual spectra of wheat straw samples (Appendix E). RSDs of less than $10 \%$ are observed at any wavelength of the raw spectra that correlates to analytes of interest; deviations of up to $10 \%$ are fairly common for the $-\mathrm{OH}$ absorbance from water, alcohols, and any other carbon-OH species. This shows the strong impact of moisture content in the sample or sample environment on the resulting measured spectra. The particle size of the sample also has a significant effect on the NIR spectrum; particle size impacts the amount of radiation scattered by the sample (Jorgensen 2000). Large particles result in a higher absorbance, thereby, they have an additive effect on the spectra; strong absorbers show more change with particle size relative to weak absorbers. Barnes et al. succinctly state that sample particle size accounts for the majority of the variance, while variance due to chemical composition is small [20]. Each of these factors will have a strong impact on measurements of

\footnotetext{
${ }^{2}$ RSD's of $1-3 \%$ are reported for glucan, xylan, lignin, extractives, and total component closure with the other minor components showing 4-10\% RSD using conventional wet chemical techniques (NREL Laboratory Analytical Procedures) [11. Templeton, D.W., et al., Compositional Analysis of Lignocellulosic Feedstocks. 2. Method Uncertainties. Journal of Agricultural and Food Chemistry, 2010. 58(16): p. 9054-9062.
} 
biomass in the field. The cost of instrumentation, laboratory costs, ease of use, scientific labor costs, and maintaining models (NIR/PLS model) and appropriate standards must also be considered when developing specifications.

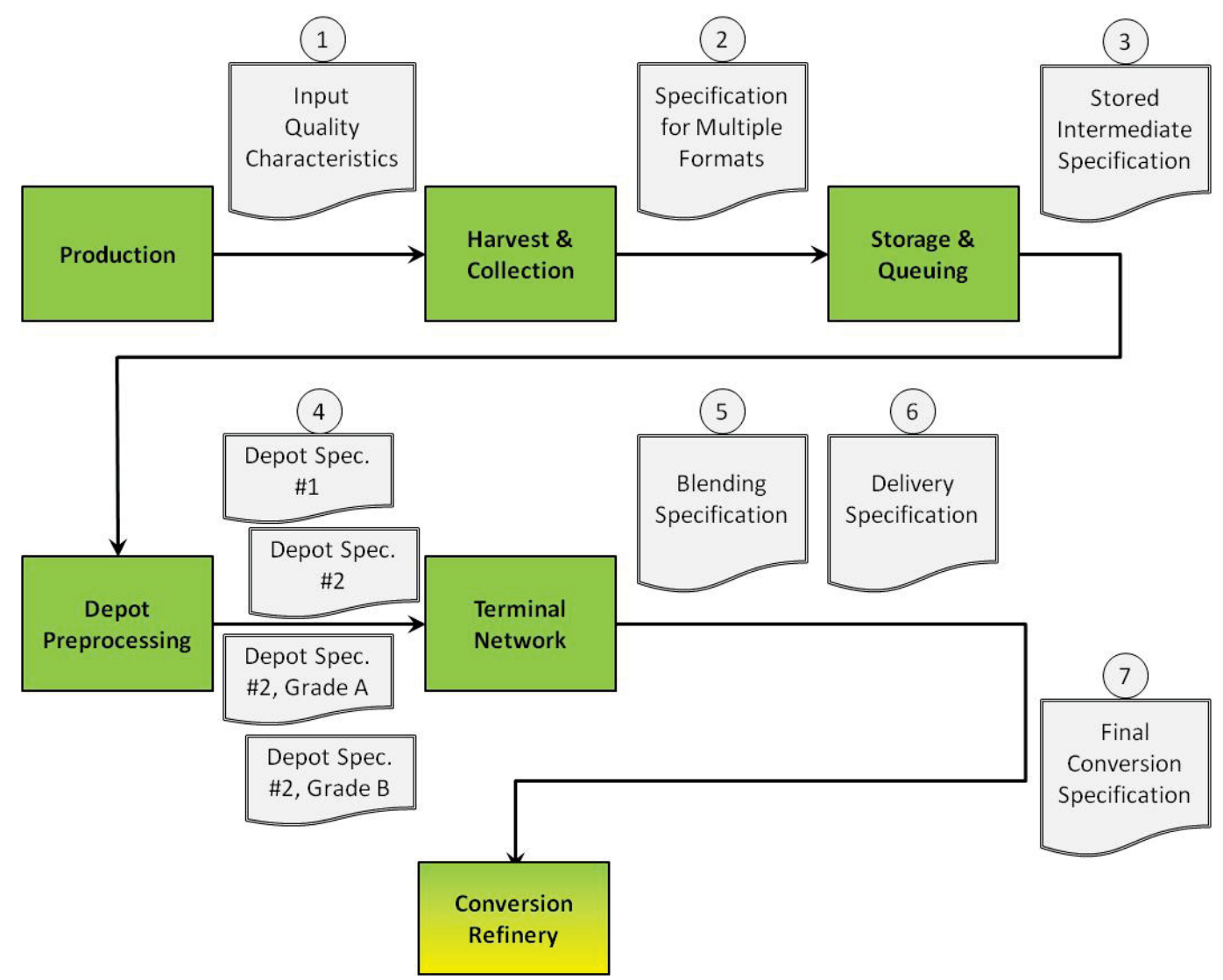

Figure 2. Example of possible intermediate specifications and the integration of preliminary and intermediate specifications that sustain the final conversion specifications within the logistical process.

\section{$\underline{\text { Key Results }}$}

\section{$\underline{\text { Intrinsic Feedstock Specifications }}$}

\section{Feedstock Specifications Review}

Four biomass feedstocks (i.e., corn stover, switchgrass, Miscanthus, and sorghum) were chosen for review. Compositional analysis information through a number of resources were reviewed and compiled to establish practical initial quality attributes for development of feedstock specifications: INL Biomass Research and Development (R\&D) Resource Library, National Renewable Energy Laboratory (NREL) Biomass Feedstock Composition and Property Database, Energy Research Centre of the Netherlands (ECN) Phyllis2 Database for Biomass and Waste, and Peer Reviewed Literature Search. An attempt was 
made to determine, for each source, whether the feedstock was field (commercially) harvested or if it was research grade (not mechanically harvested). The compilation tables of these research methods are located in Appendix A (corn stover), Appendix B (switchgrass), Appendix C (Miscanthus), and Appendix D (sorghum). The compilation results from these resources are shown in Tables 7 through 10. Tables 7 through 10 are the mean results from the four different resources used to determine composition for the feedstocks of interest. They have been split into field harvest and research grade/unknown.

\section{Methods}

\section{Search Information}

Four feedstocks were selected for the database and literature search, including corn stover, switchgrass, Miscanthus, and sorghum. Only untreated samples with chemical composition were compiled. Specific parameters of interest were structural sugars (i.e., glucan, xylan, galactan, arabinan, and mannan), cellulose, hemicellulose, lignin (i.e., klason, acid soluble, and acid insoluble), and ash. Samples were broken into three categories: (1) field harvest, (2) unknown, and (3) research grade. Samples were considered field harvested if there were some details indicating the samples were harvested with large-scale equipment, and research grade samples were collected by hand. Samples were categorized as unknown if it could not be determined if the samples were field harvested or research grade. Three biomass databases and peer-reviewed literature were used for the analysis search.

\section{INL Biomass Resource Library}

Biomass samples that were treated in any way were excluded from the report. Samples were categorized as field harvested if they were stored in bale format and research grade samples had no large harvesting equipment or bale format included in the sample information. Also, personal conversations with the librarian for the INL Biomass Library and/or principal investigators for specific projects were used to correctly categorize samples as field harvest or research grade.

\section{NREL Biomass Feedstock Composition and Property Database}

The NREL database was searched for chemical composition data from untreated samples of the four selected feedstocks. No information was available for Miscanthus. The database entries are from various sources, but minimal harvest information was output with each entry. The sources were not individually investigated for harvest information. If a bale format was listed, samples were considered field harvested. Most samples were considered unknown (i.e., not research grade or field harvested).

\section{ECN Phyllis2 Database for Biomass and Waste}

The Phyllis2 database was searched for chemical composition data for untreated samples for the four selected feedstocks. The database was not searchable by harvest method; therefore, all samples from the Phyllis2 database were considered unknown (i.e., not research grade or field harvested).

\section{Peer-Reviewed Literature Search}

Google Scholar and Web of Science were used to find peer-reviewed articles related to biomass feedstock chemical composition. A thorough search was completed for field-harvested biomass and articles were included if the methods section explicitly stated that the biomass in the study was from a commercial-scale field or that the material was from a bale or other large-scale harvesting process. Articles were included as research grade materials if the methods explicitly stated that the biomass was 
harvested by hand. If it was not clear from the methods in the article whether the material was field harvested or research grade, it was considered unknown.

\section{Intrinsic Feedstock Specifications}

The evolution and development of feedstock specifications will initially mature from solid analytical data for the feedstock and quality characteristics of interest, as well as defined performance and secondary drivers. For the purposes of this document, the performance drivers are not included at this time; only the intrinsic characteristics of the biomass feedstocks are discussed. Unfortunately, as seen in the data, not all analytical information (e.g., $\% \mathrm{H}_{2} \mathrm{O}, \% \mathrm{Ash}, \%$ Carbohydrate, recalcitrance (convertibility), inhibitor content, elemental content, and particle size distribution) is readily available or complete for each sample set, with few comprehensive data sets, which clearly delineate the plant species, method of harvest (as shown previously, ash concentrations can vary, impacting carbohydrate content), or method of storage. The method of storage directly impacts dry matter loss and can decrease convertibility [21]. Nonetheless, the compilation of data does provide insight into some fundamental quality characteristics that are consistent with other assumptions and targeted research.

Mean compositional values for corn stover from four sources for research grade/unknown material is $58.5 \%$ for the combined sugars content and $64.0 \%$ for combined cellulose/hemicellulose content, with an overall mean of $61 \%$ (mean sugar + cellulose/hemicellulose content). Respective mean ash content is $6.1 \%$. Mean compositional values for corn stover from four sources for field-harvested material is $59.9 \%$ for the combined sugars content and $58.3 \%$ for combined cellulose/hemicellulose content, with a overall mean of $59 \%$ for field-harvested corn stover materials. Respective mean ash content is $7.2 \%$.

Mean compositional values for switchgrass from four sources for research grade/unknown material is $61.2 \%$ for the combined sugars content and $64.1 \%$ for combined cellulose/hemicellulose content, with an overall mean of $63 \%$. Respective mean ash content is $7.0 \%$. Mean compositional values for corn stover from four sources for field-harvested material is $62.1 \%$ for the combined sugars content and $62.0 \%$ for combined cellulose/hemicellulose content, with a overall mean of $62 \%$ for field-harvested switchgrass. Respective mean ash content is $5.6 \%$.

Mean compositional values for Miscanthus from four sources for research grade/unknown material is $64.2 \%$ for the combined sugars content and $70.5 \%$ for combined cellulose/hemicellulose content, with an overall mean of $67 \%$. Respective mean ash content is $8.3 \%$. Mean compositional values for Miscanthus from four sources for field-harvested material is $63.6 \%$ for the combined sugars content. Respective mean ash content is $5.0 \%$.

Mean compositional values for sorghum from four sources for research grade/unknown material is $54.2 \%$ for the combined sugars content and $49.9 .7 \%$ for combined cellulose/hemicellulose content, with an overall mean of $52 \%$. Respective mean ash content is $5.1 \%$. Mean compositional values for sorghum from four sources for field-harvested material is $59.3 \%$ for the combined sugars content and $51.7 \%$ for combined cellulose/hemicellulose content, with a overall mean of $56 \%$ for field-harvested sorghum materials. Respective mean ash content is $12.0 \%$. 
Corn stover has the most comprehensive data sets available and the overall mean carbohydrate content of $59 \%$ determined for field-harvested corn stover is consistent with initial assumptions (as seen in Table 6). The mean ash content of 7\% for field-harvested corn stover is consistent with observed data (see Table 5), but exceeds the assumed ash specification by $2 \%$. This variability can be expected because the impact of collection equipment on ash variability is significant [9]. Logistics solutions, including single-pass harvesting, are being investigated to reduce excessive feedstock ash content attributed to introduced ash that results from entrainment of soil in the biomass during harvest. Development of single-pass harvest systems will help mitigate this issue. Comprehensive data on single-pass harvesting systems is limited. Preliminary data for single-pass corn stover indicates that ash content below $3.5 \%$ and a total carbohydrate content of $66 \%$ is achievable [22]. Further harvest studies and characterization of singlepass baled corn stover is needed to determine more comprehensive values. Results from multi-pass harvest studies and characterization of multi-pass baled corn stover using best harvesting practices are forthcoming and should provide clarification to intrinsic corn stover specifications for multi-pass harvesting.

Although there is limited large-scale harvesting and storage experience with switchgrass for bioenergy production [23], there are considerable data sets available for review. The overall mean carbohydrate content of $62 \%$ and $63 \%$ determined for research grade/unknown material and field-harvested switchgrass, respectively, should be considered preliminary as feedstock logistics and refinery demand will influence optimal harvesting operations. Wyman et al. [23] indicated that compositional differences are more strongly dependent on harvesting time than variety. The mean ash composition of $7.0 \%$ and $5.6 \%$ determined for the research grade/unknown and field-harvested switchgrass, respectively, supports that these values are preliminary as well, because the ash content for the research/unknown materials is higher than the field-harvested material.

The available data sets for Miscanthus and sorghum are more limited and efforts are currently ongoing to establish comprehensive compositional data for these feedstocks [24]. The overall mean carbohydrate content of $67 \%$ for research grade/unknown Miscanthus and the mean compositional values of $63.6 \%$ for the combined sugars content for the field-harvested Miscanthus are preliminary due to the lack of comprehensive data. Liu et al.[25] showed that four Miscanthus species displayed different plant structure compositions, biomass yields, and chemical composition. The nursery-grown, hand-harvested ash content for the four Miscanthus species varied from 3.1 to $6.0 \%$ and the combined glucan, xylan, and araban content varied from 56 to $66 \%$. Therefore, initial compositional specifications should be created for each Miscanthus species, or at a minimum for those Miscanthus species with similar chemical compositions, as data becomes available. The compositional data for sorghum are disparate and incorporate both forage and sweet sorghum species; field harvest compositional data are limited. The overall mean carbohydrate content of $52 \%$ and $56 \%$ was determined for research grade/unknown sorghum material and fieldharvested sorghum, respectively; ash content for the limited harvest data was $12 \%$ and the ash content of the research grade/unknown material was 5\%. This indicates that introduced ash that results from entrainment of soil in the biomass during harvest is contributing to the \%total ash in the field-harvested sorghum data. William et al. [26] determined that the field dried, multi-pass carbohydrate content of sweet sorghum and forage sorghum to be $55 \%$ and $60 \%$, respectively; total ash content was not determined. As with Miscanthus, the initial sorghum compositional specifications should be created for sweet and forage sorghum as data become available. Currently, the data provide a rough quality 
specification for each of these feedstocks; additional compositional data are needed to establish a more robust intrinsic specification for these feedstocks. 

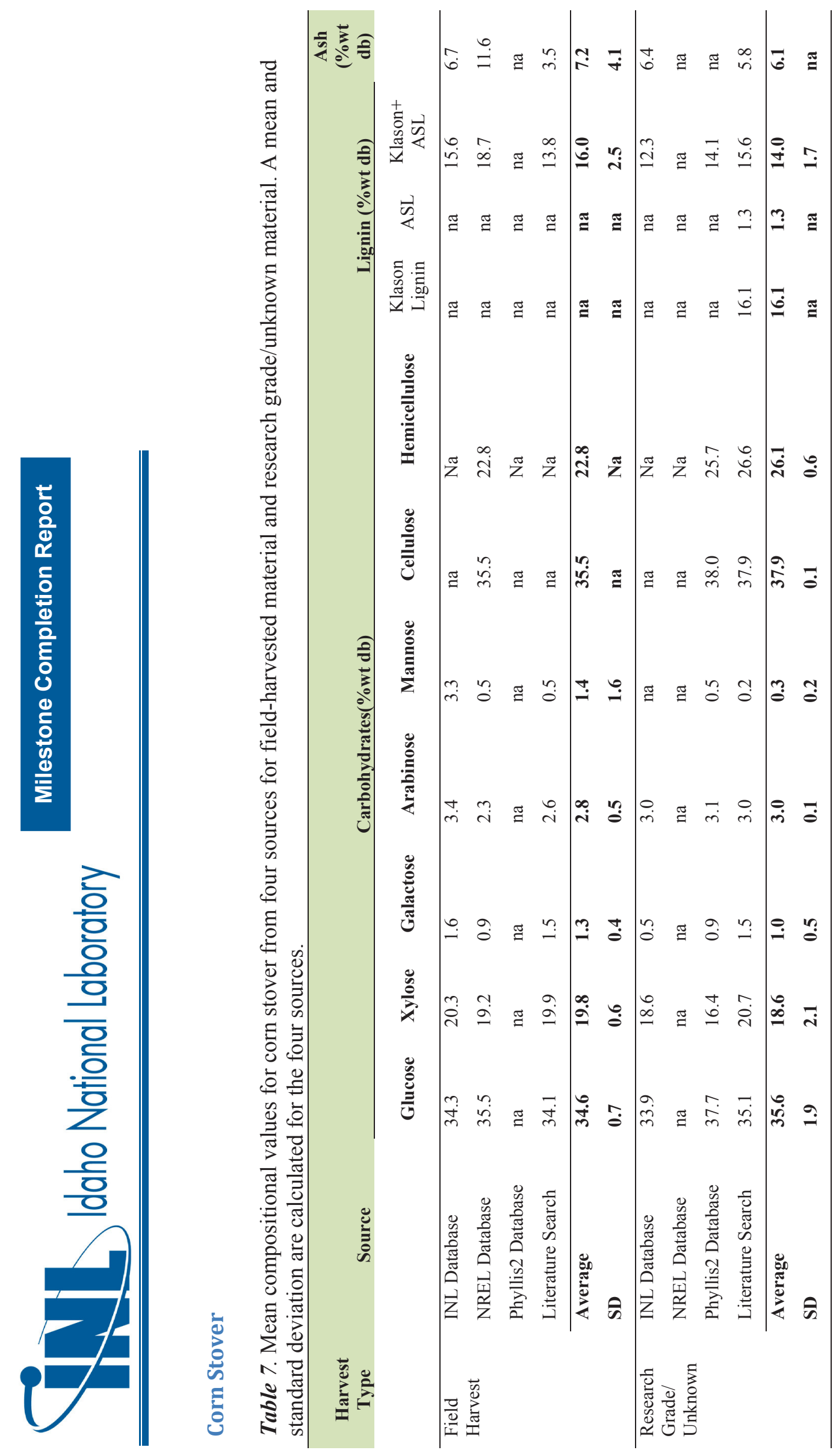

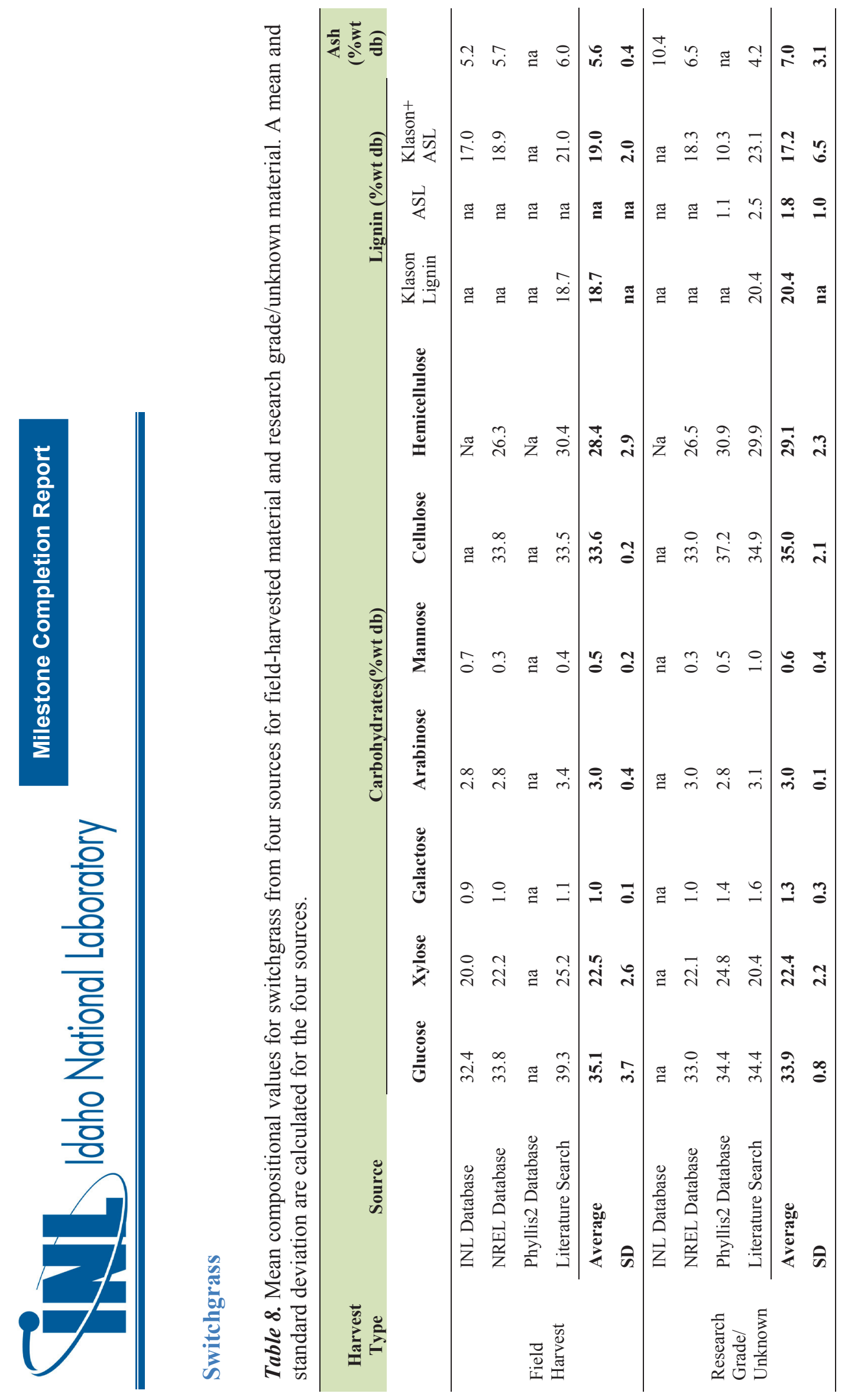

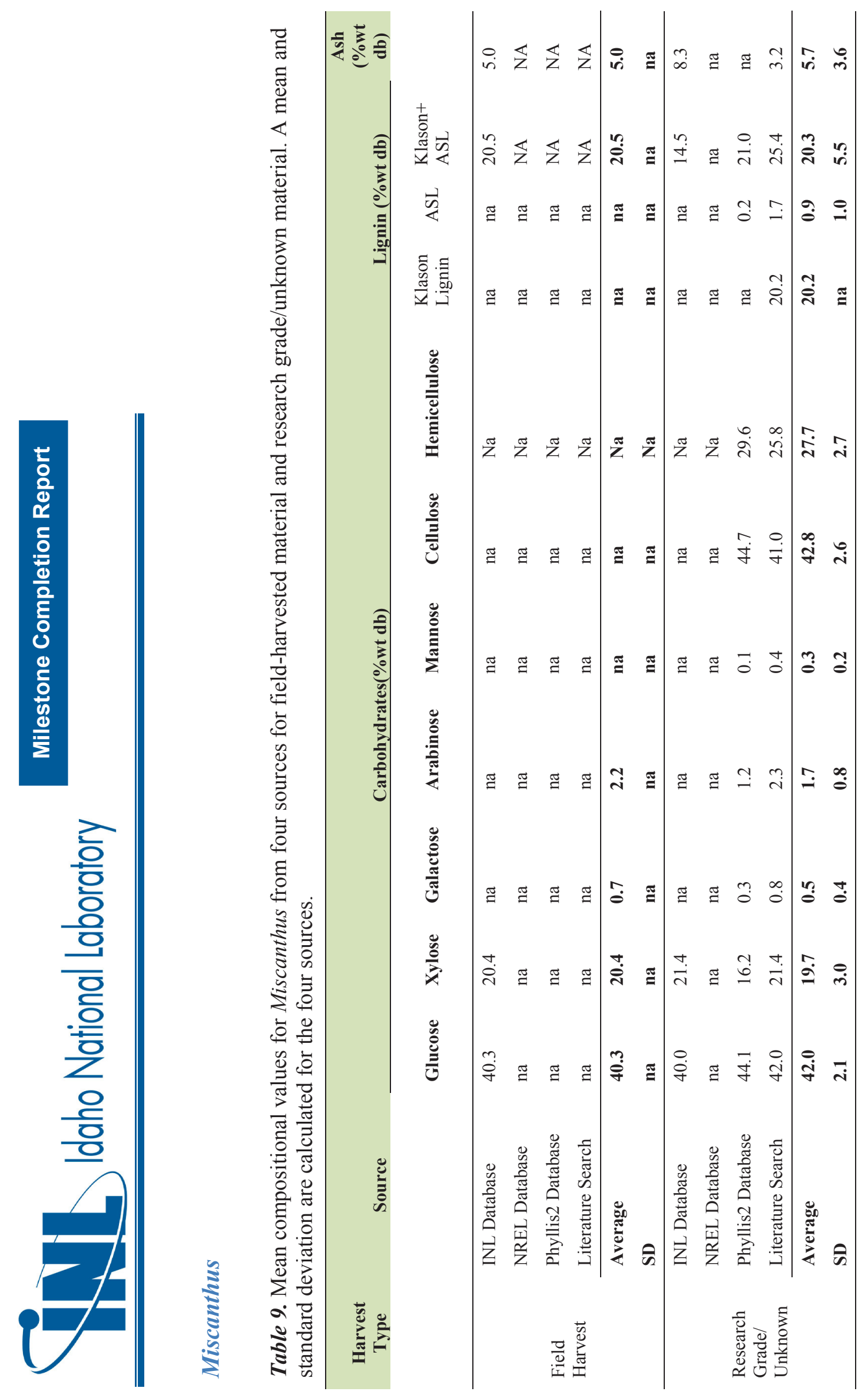


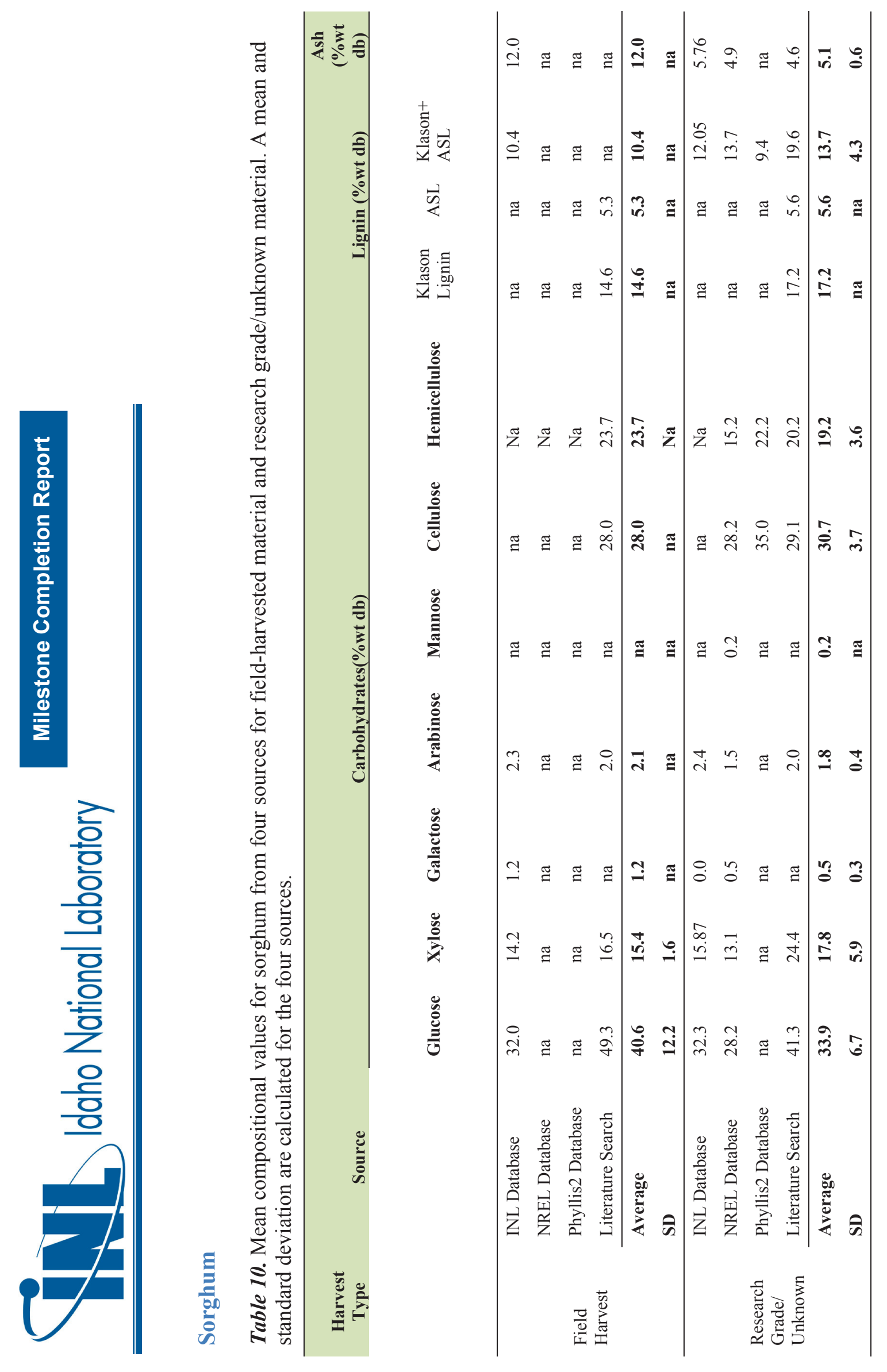




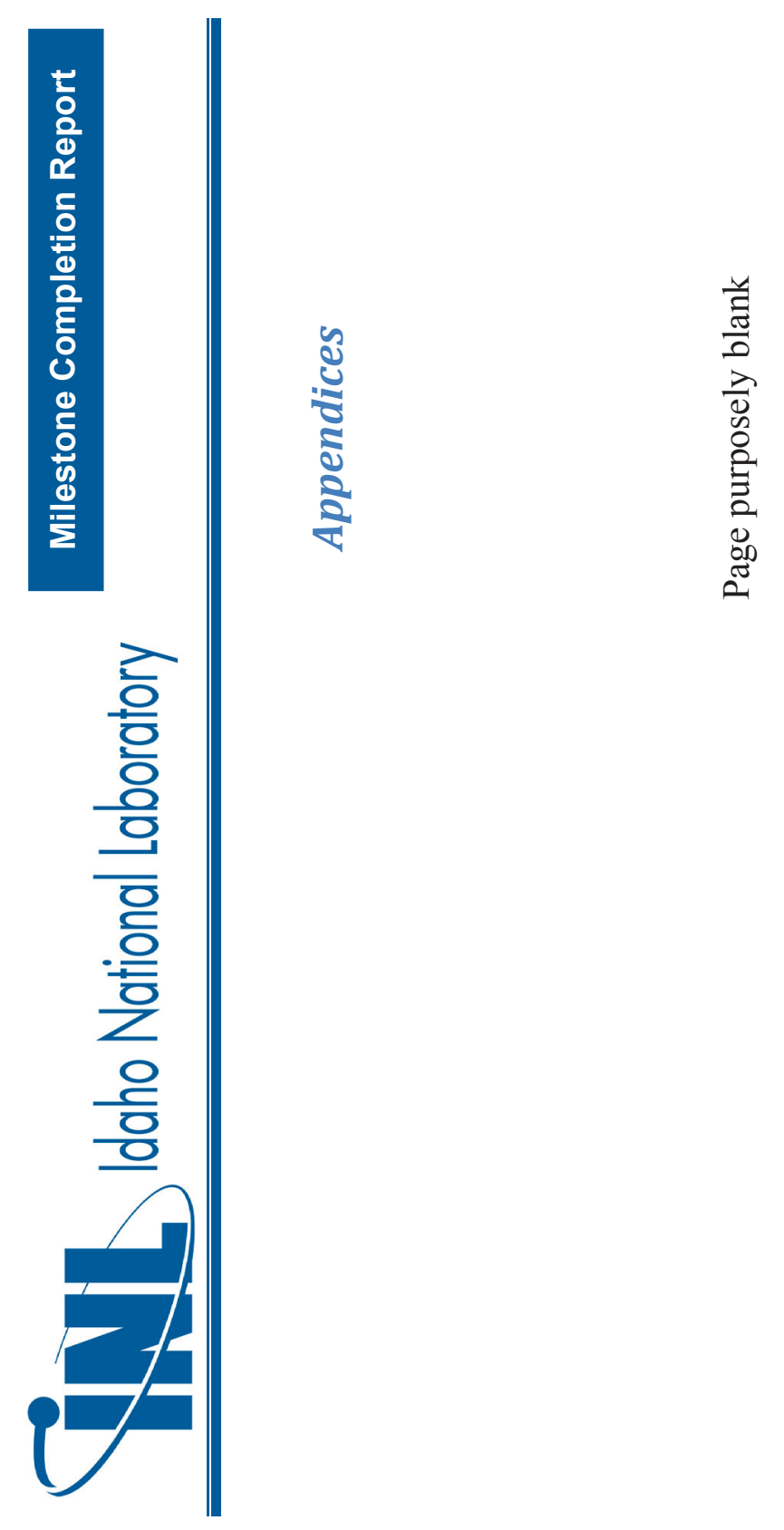




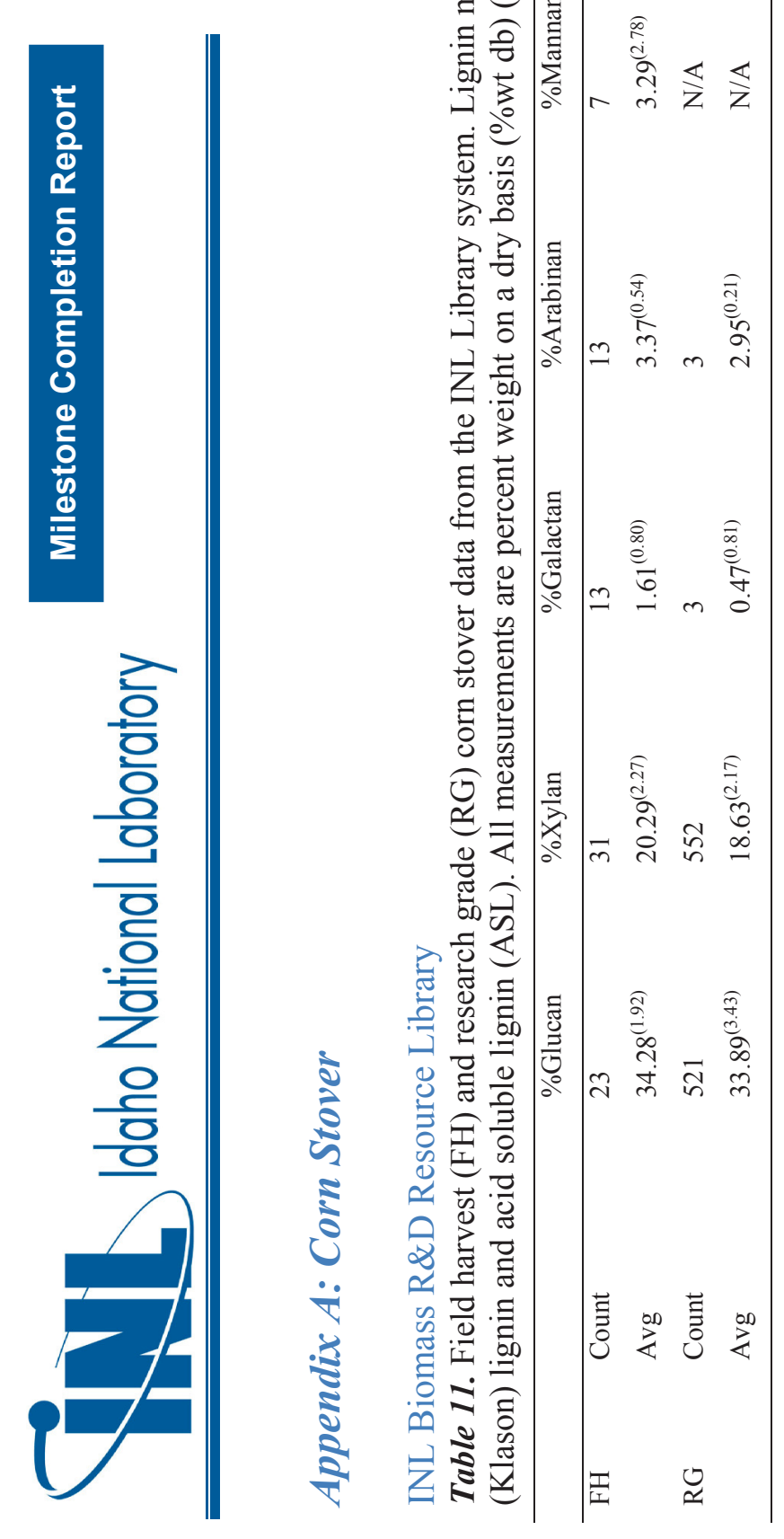




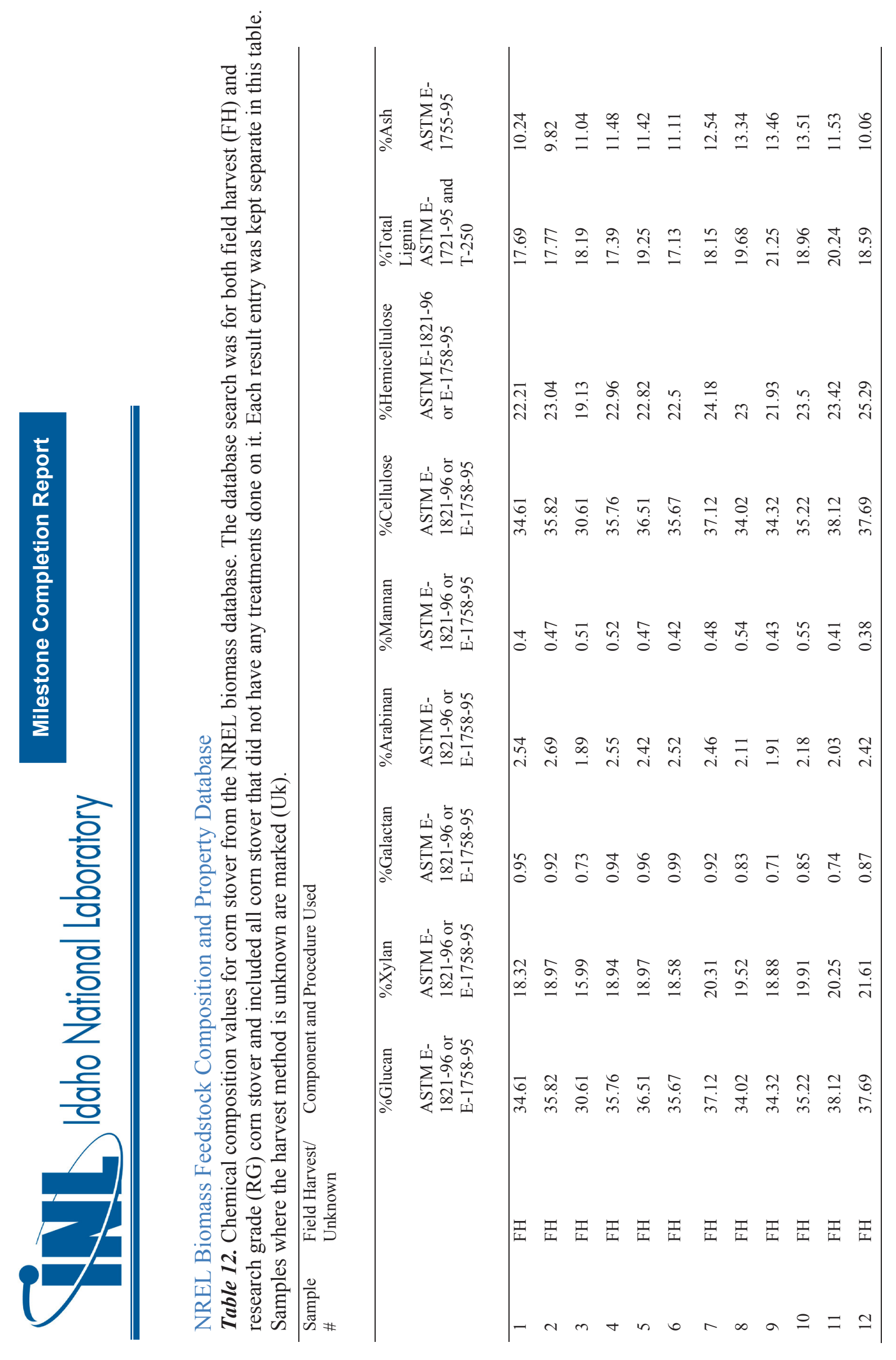

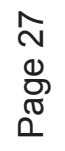




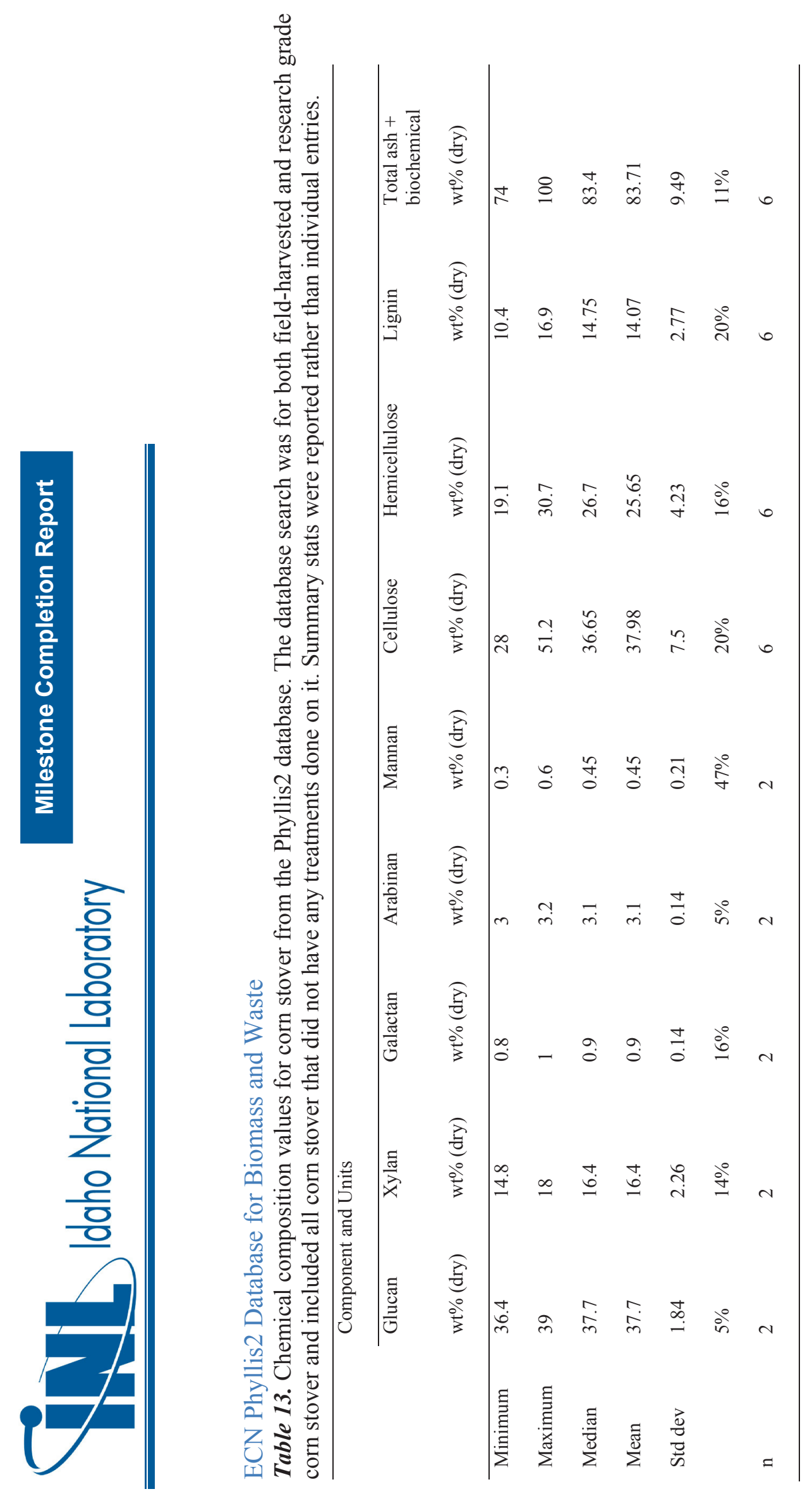

$\infty$
$\stackrel{\infty}{0}$
$\stackrel{0}{0}$
0 


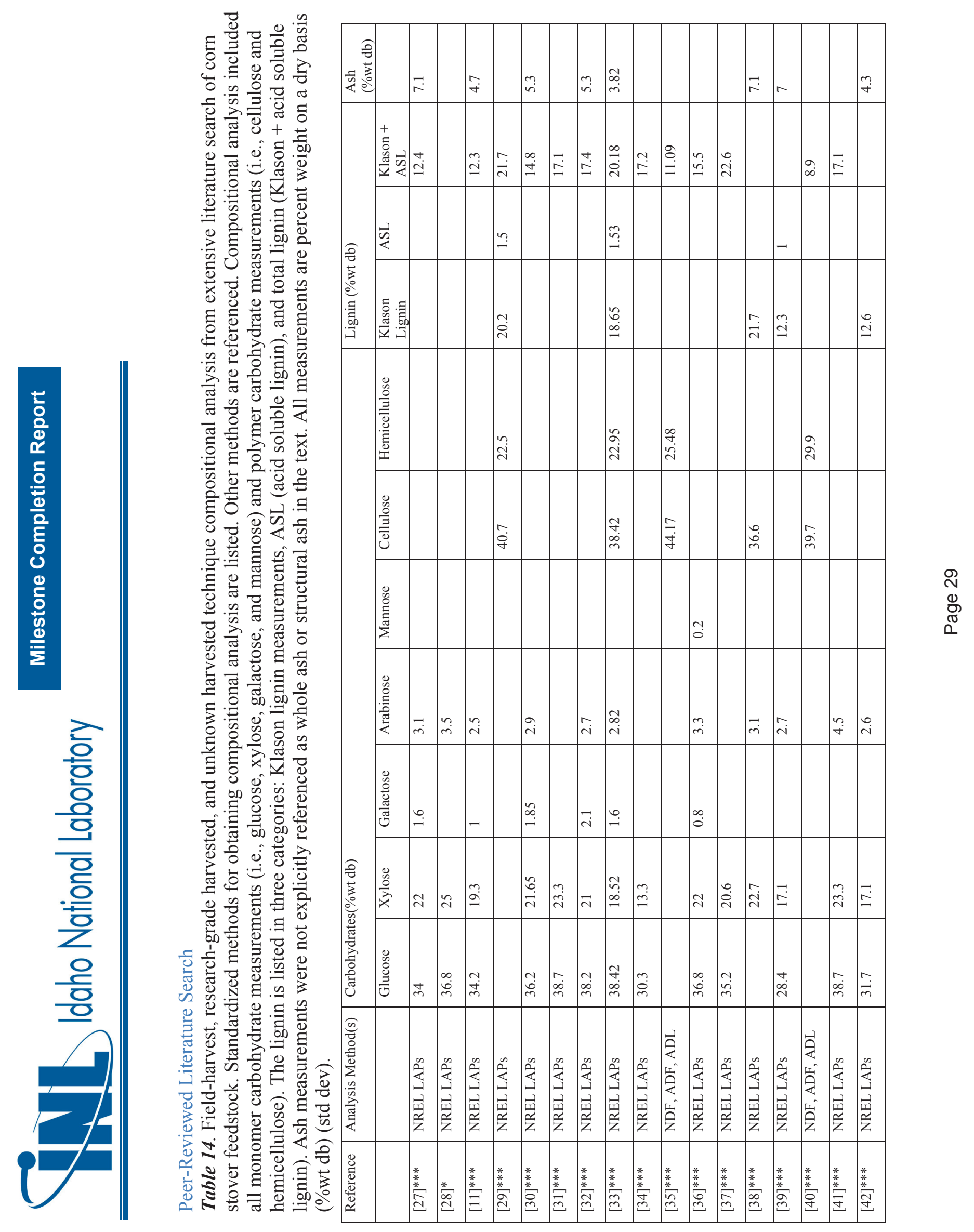




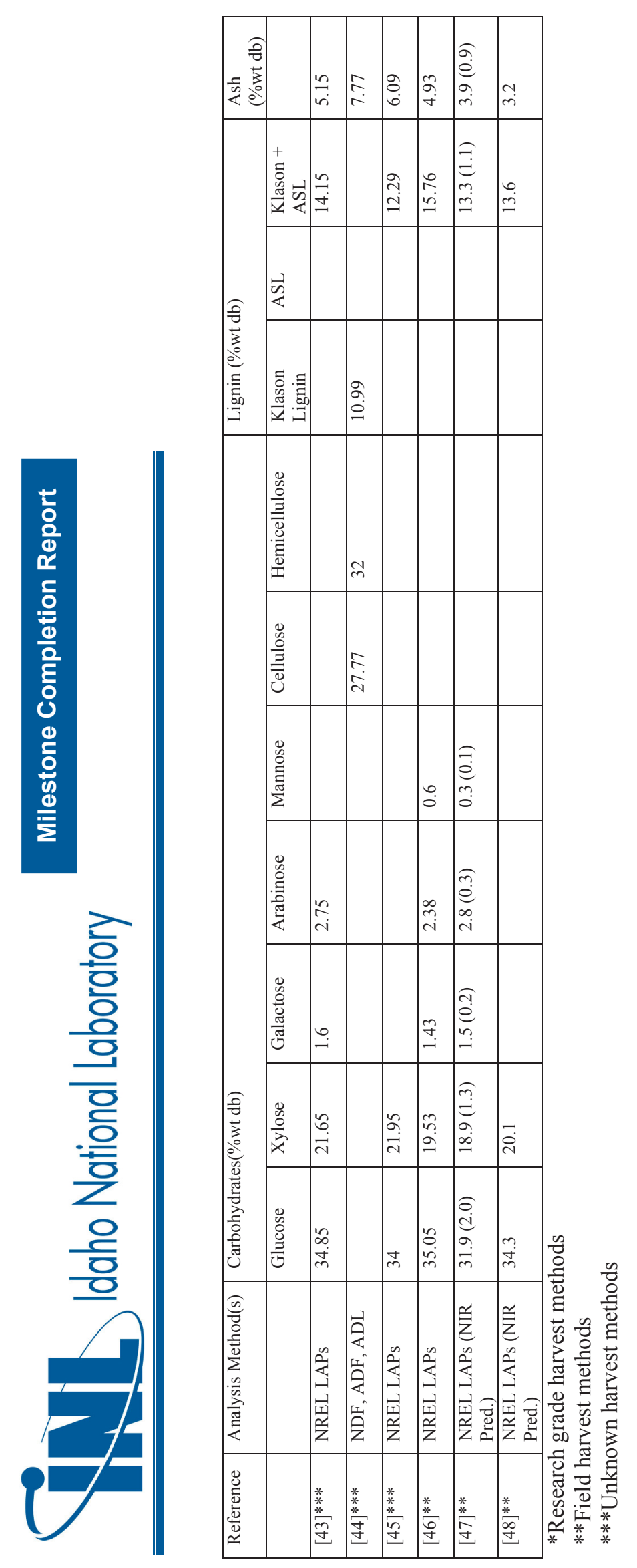

0
0
0
0
0 


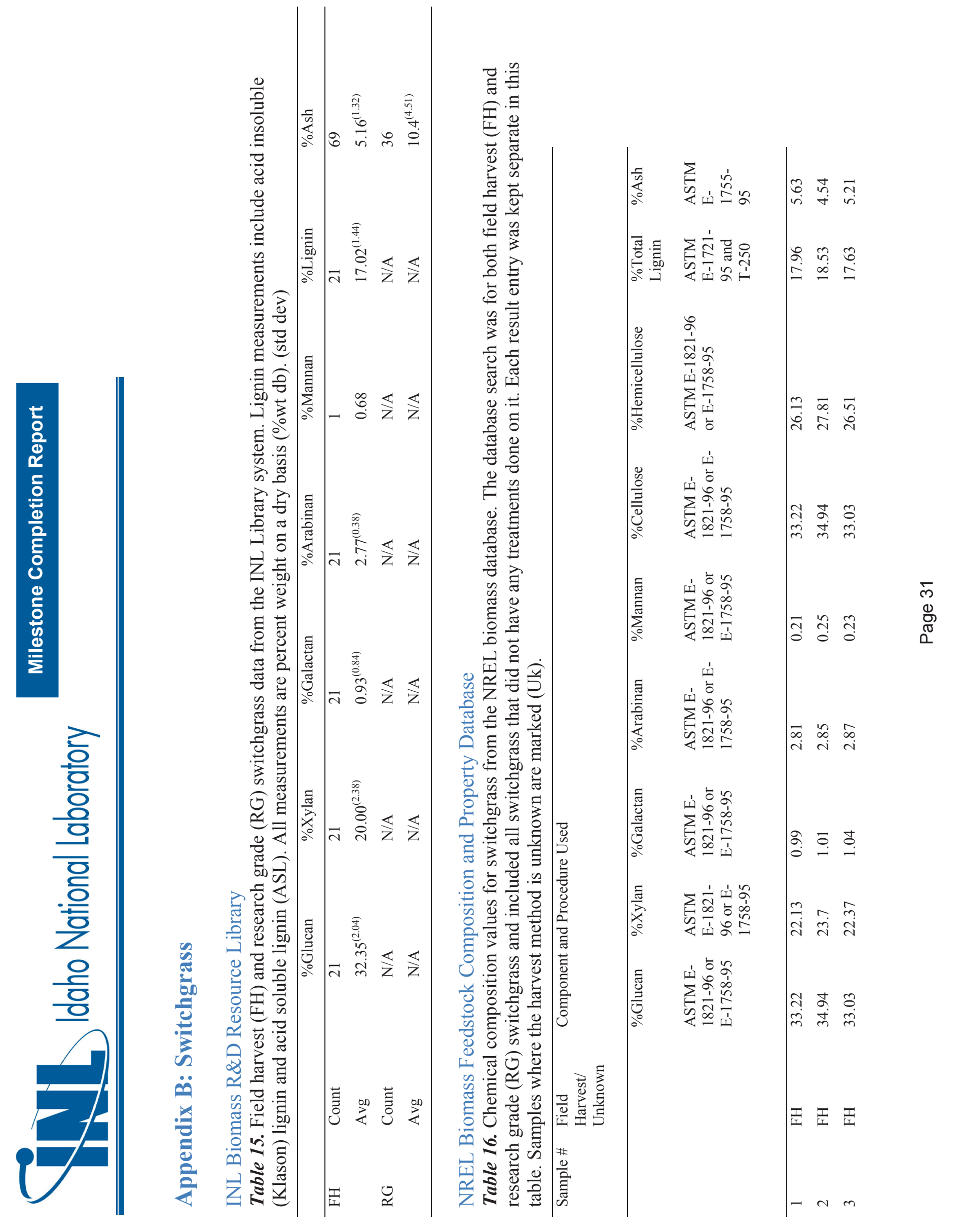




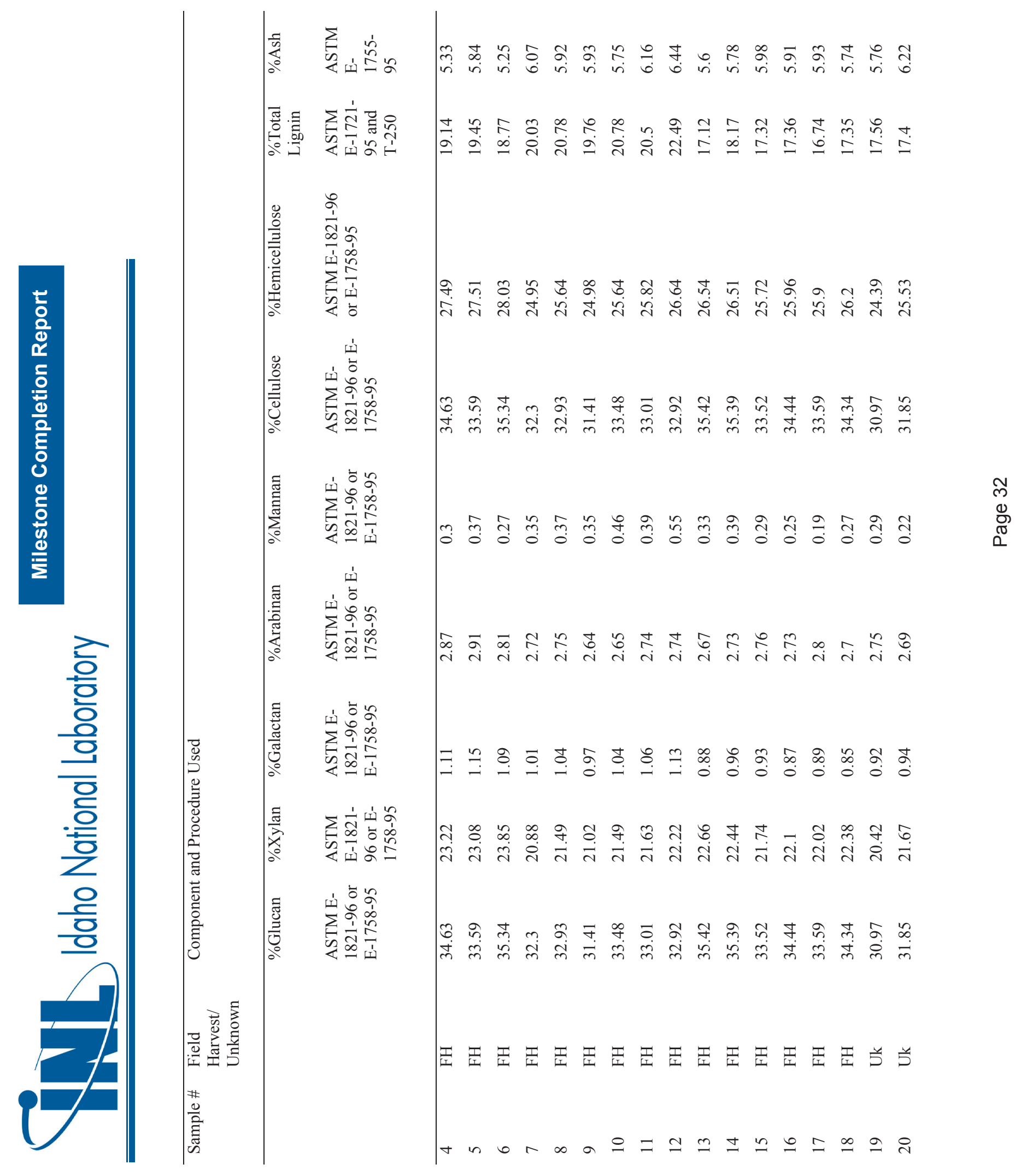




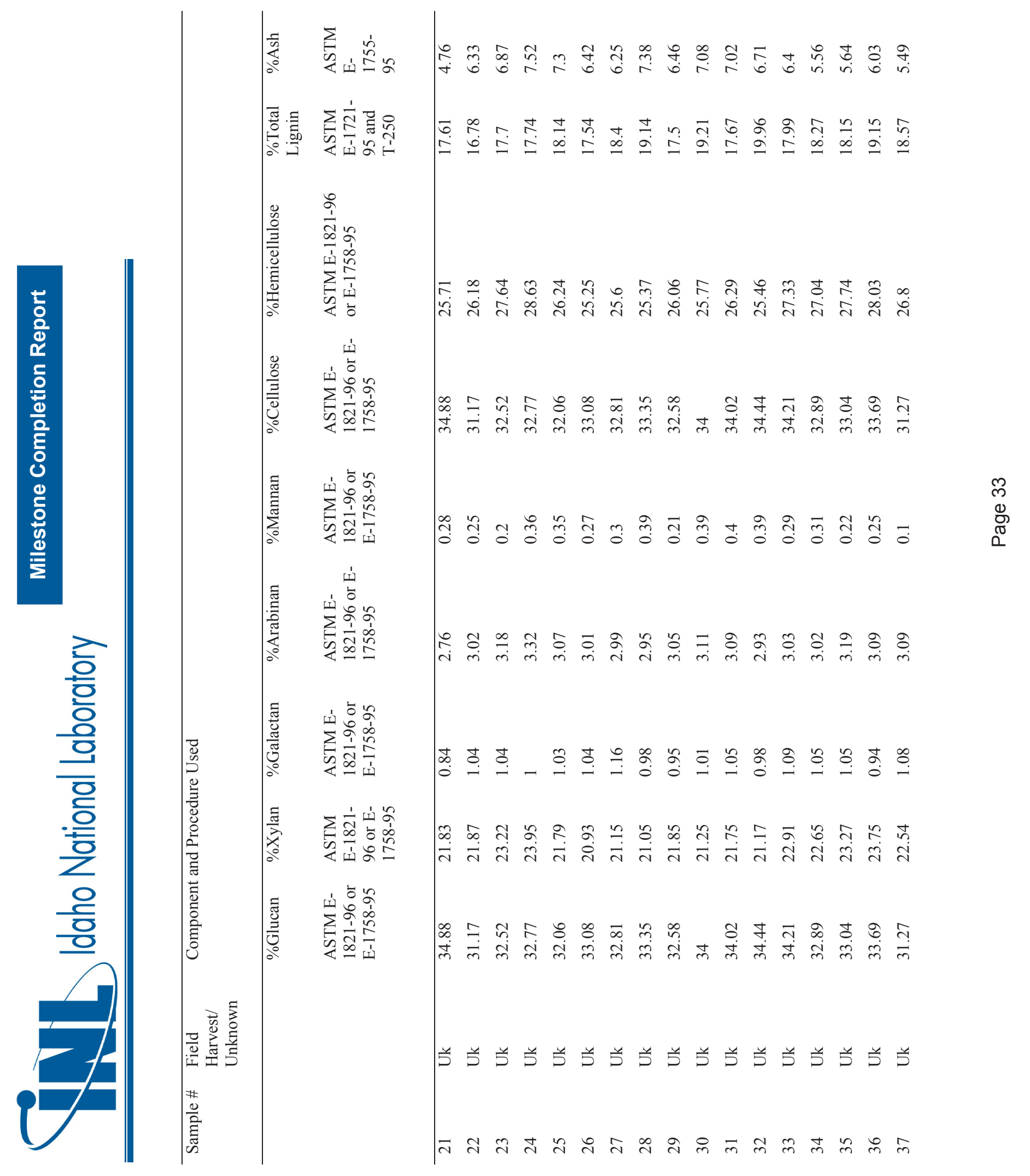




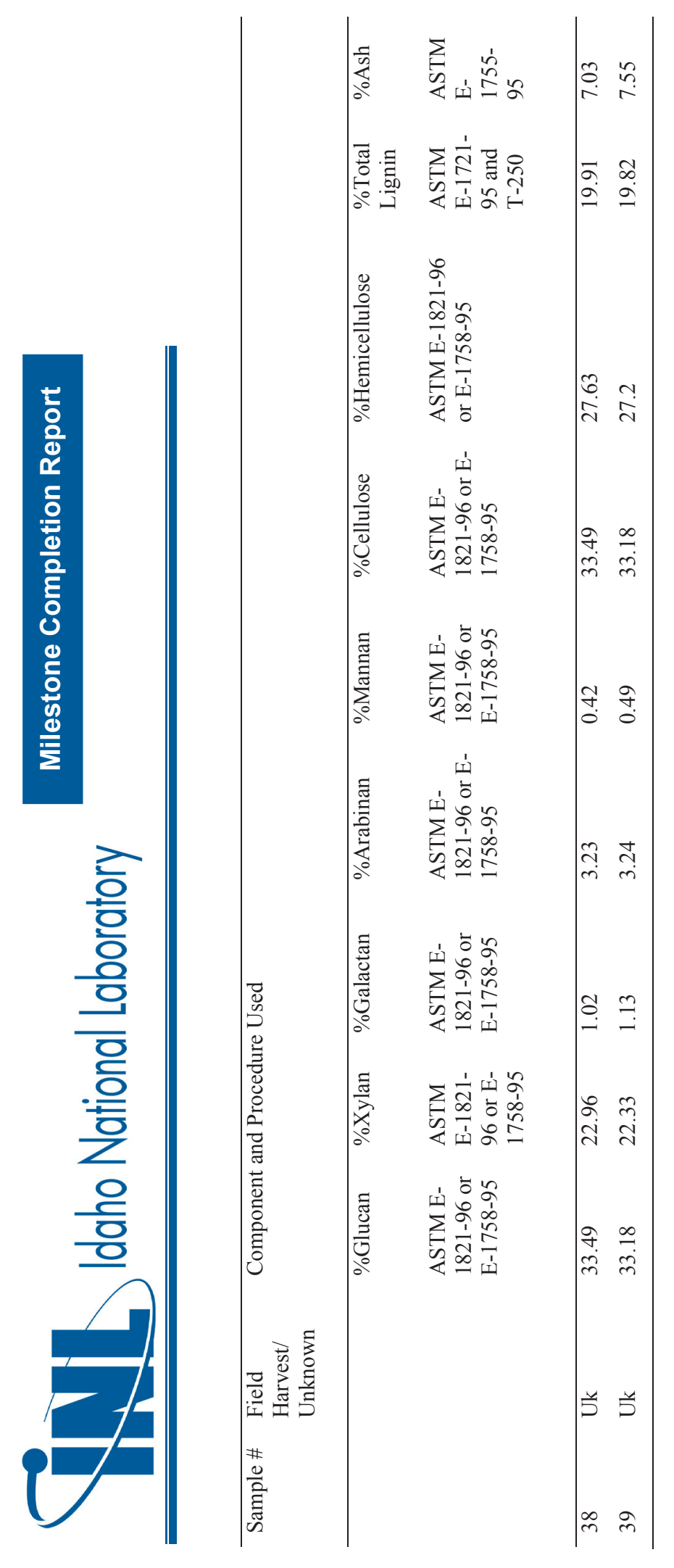

m
$\stackrel{0}{0}$
வ 


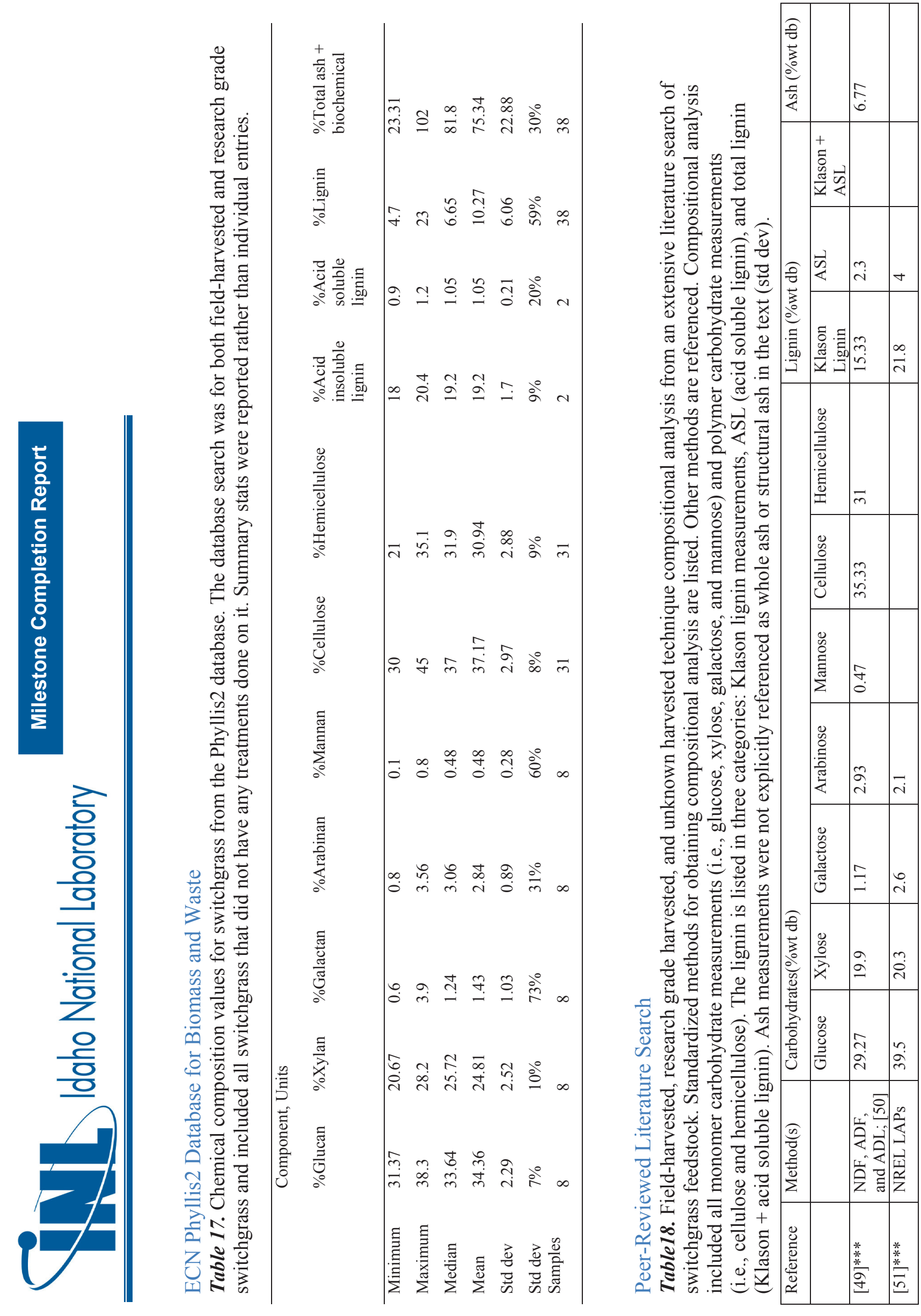

$\stackrel{1}{m}$
0
$\stackrel{0}{\pi}$
0 

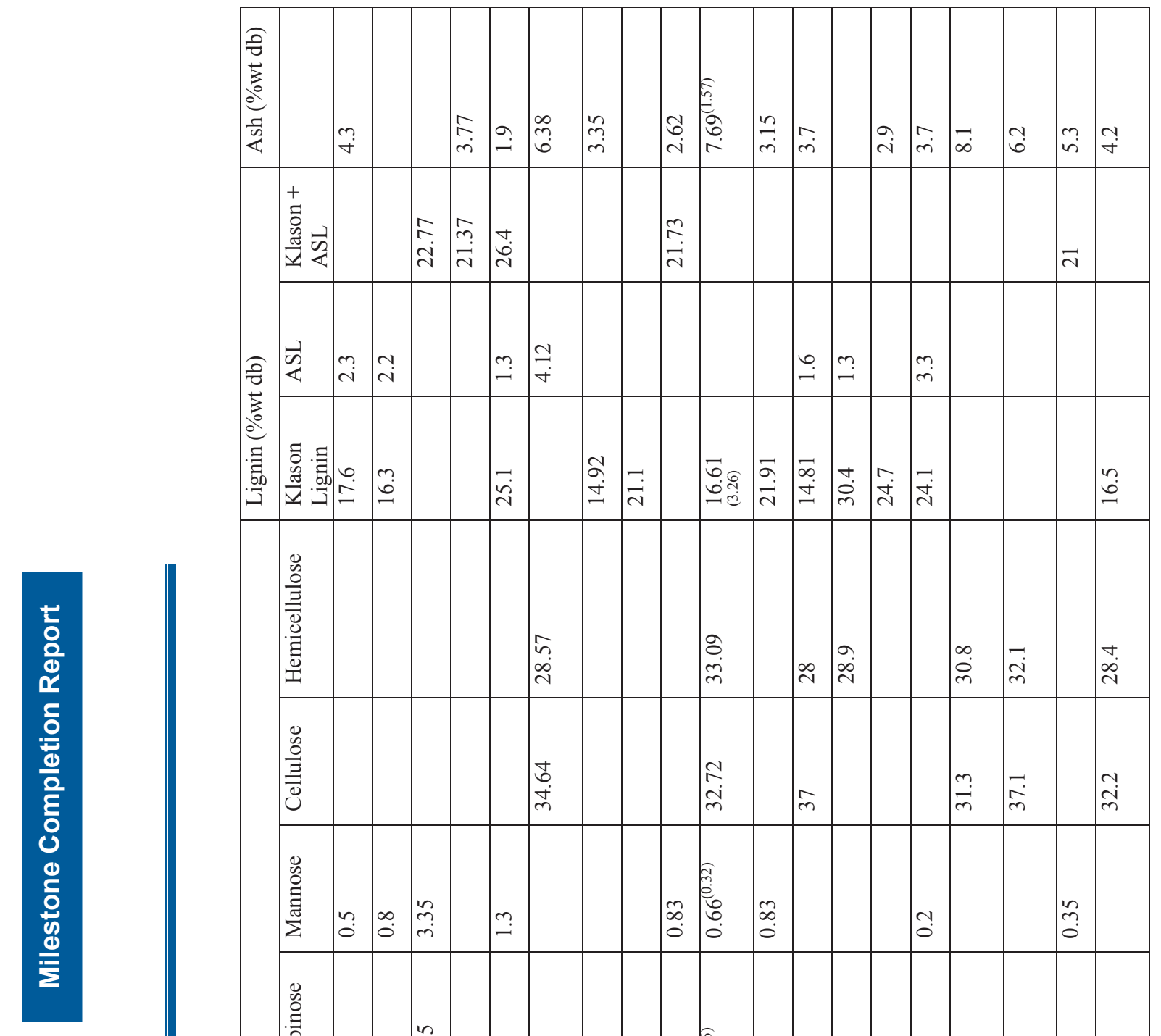

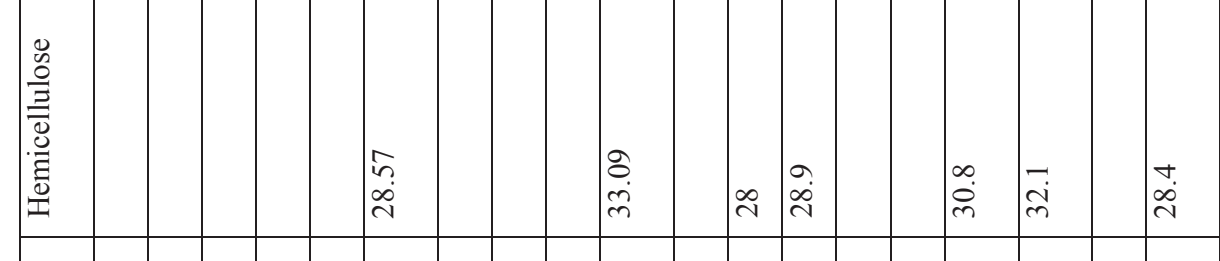

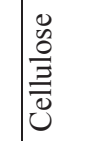

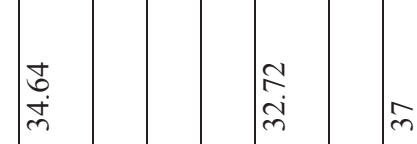

离

in

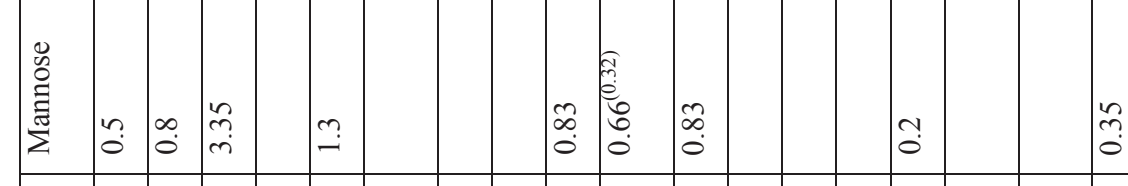

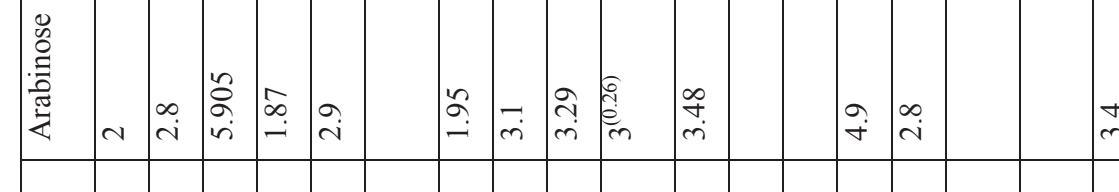

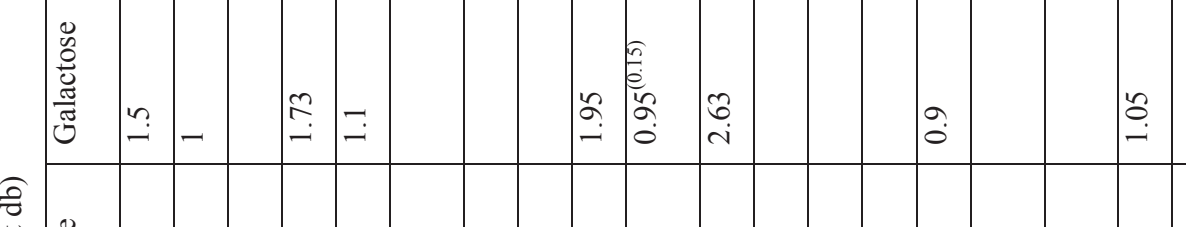

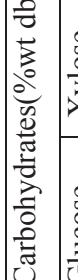

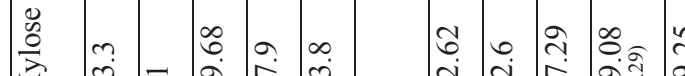

$\begin{array}{lll}0 & \\ 0 & 0 \\ 0 & 0 \\ 0\end{array}$

过

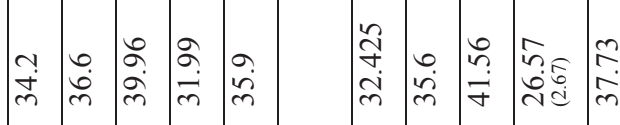

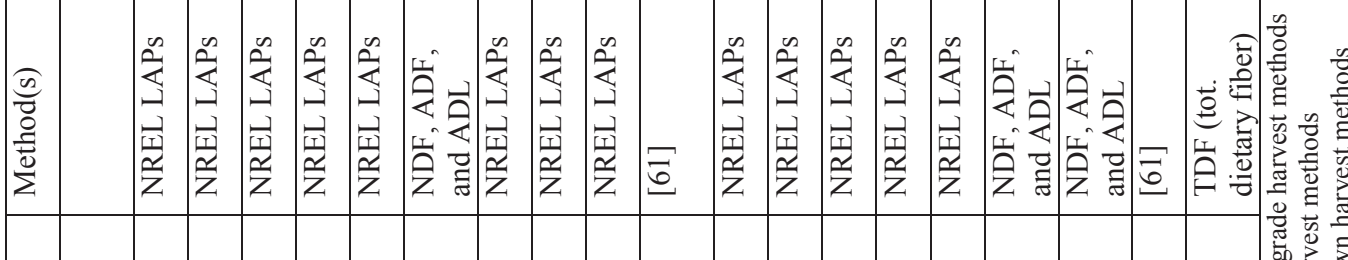

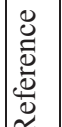

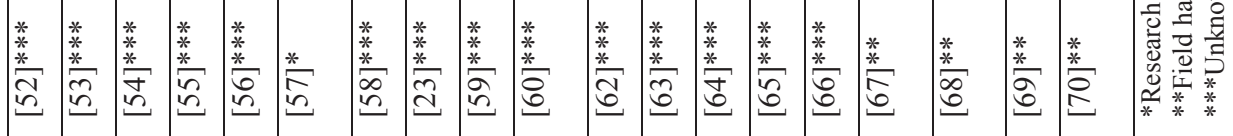




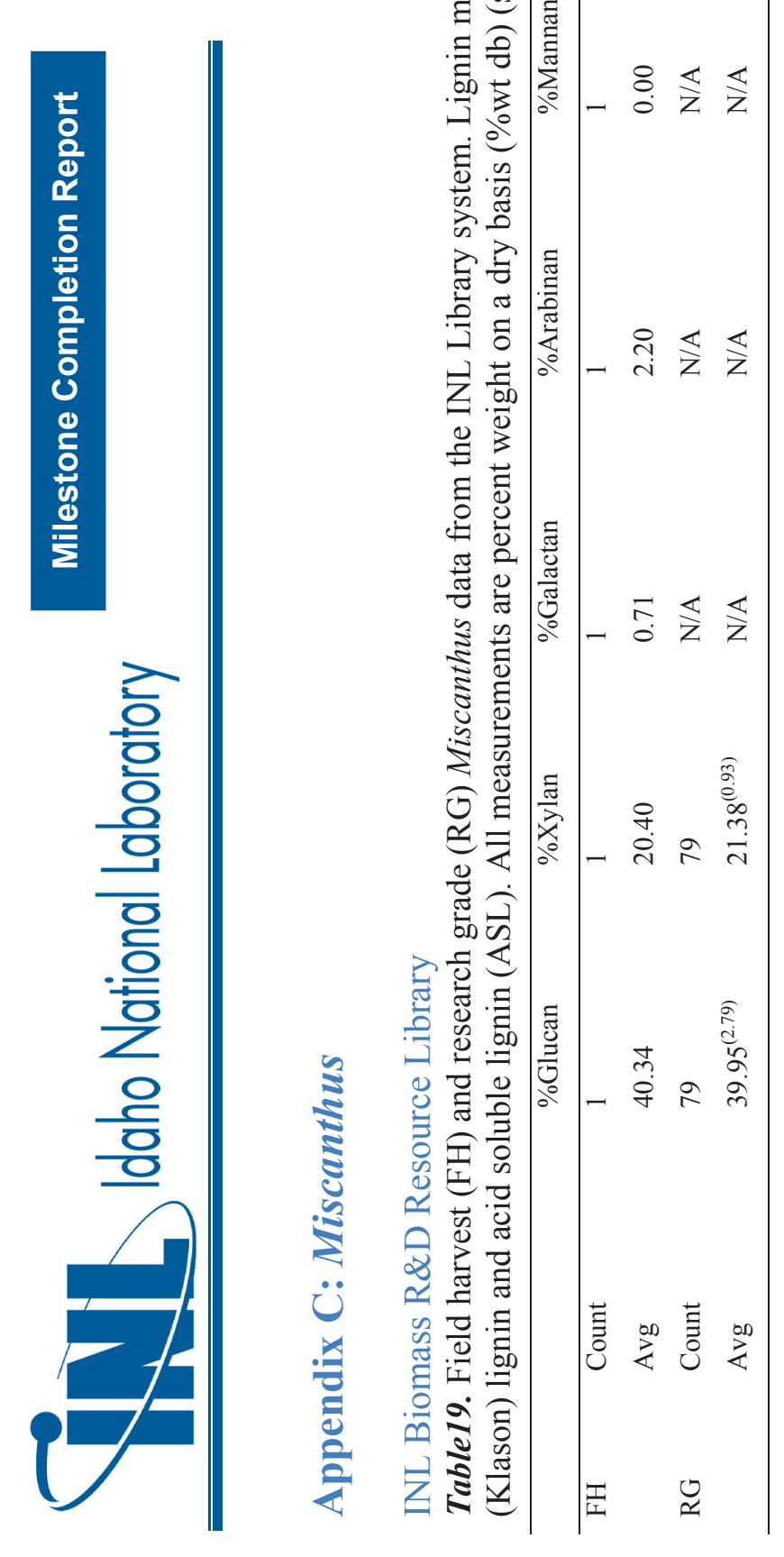

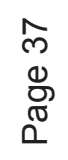




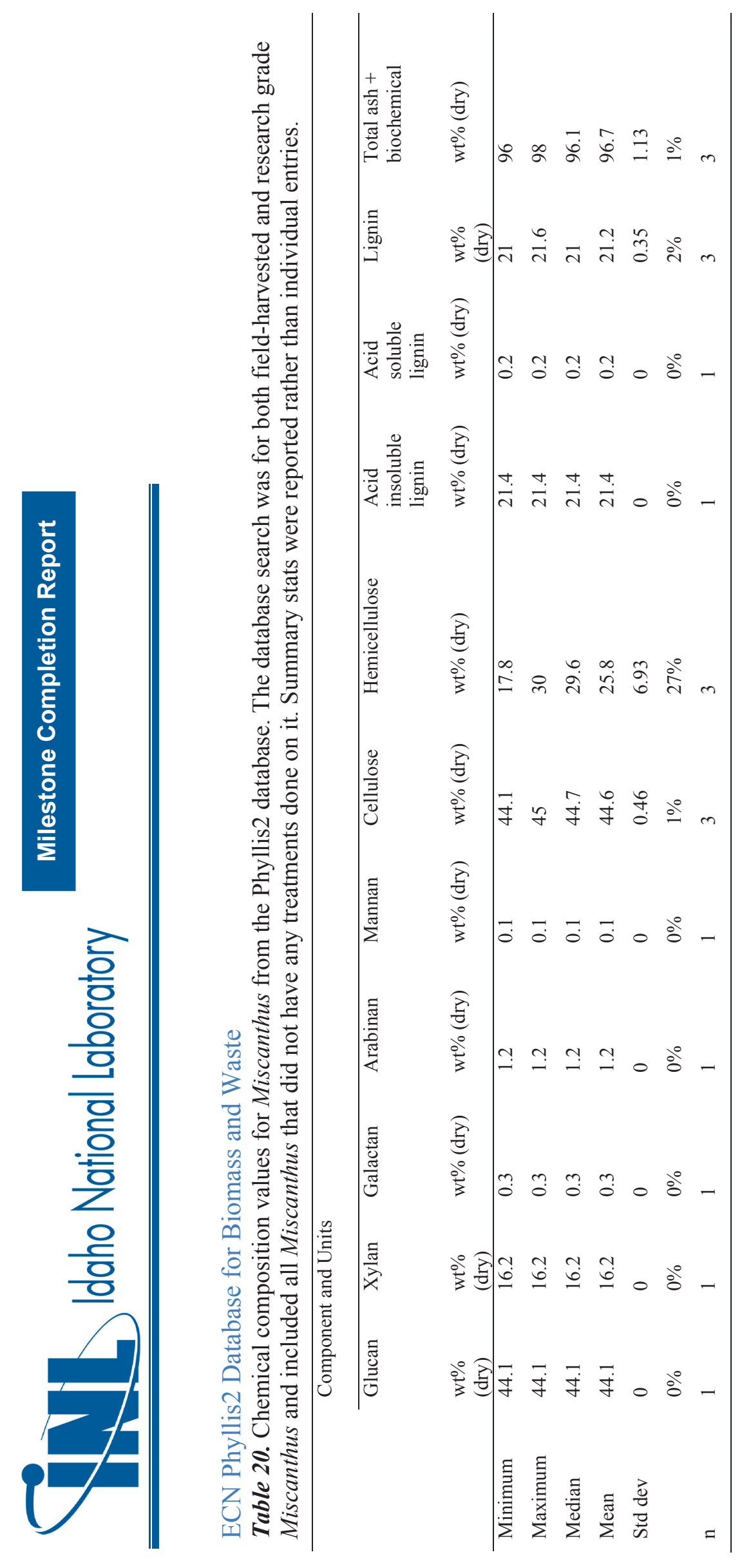

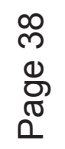




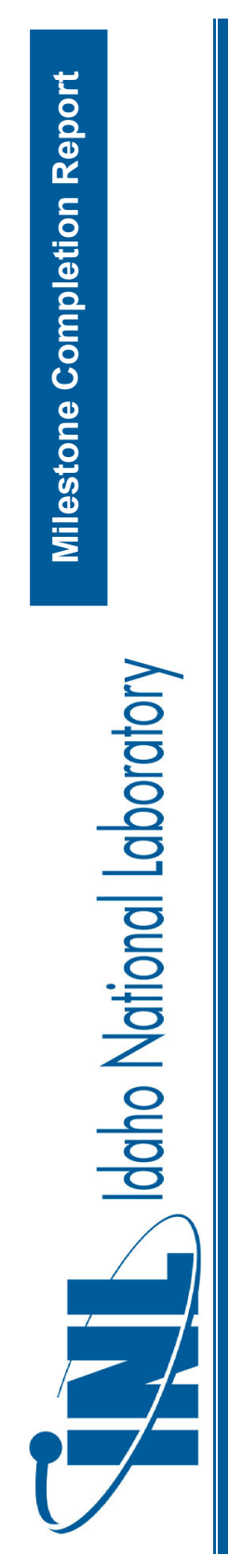

\begin{tabular}{|c|c|c|c|c|c|c|c|c|c|c|c|c|c|c|c|}
\hline 峁恋 & 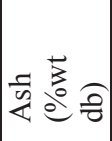 & & & $\stackrel{m}{\rightarrow}$ & & 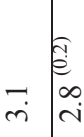 & 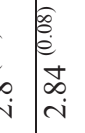 & & $\begin{array}{l}a \\
i \\
i\end{array}$ & \% & Î & 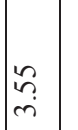 & & $\begin{array}{l}n \\
\hat{\infty} \\
\infty \\
\dot{\gamma} \\
\dot{\gamma}\end{array}$ & in \\
\hline 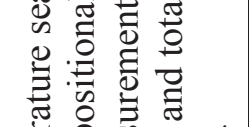 & & 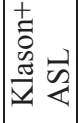 & & $\mid$ & ?ִ. & 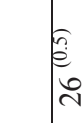 & $\begin{array}{l}\vec{n} \\
\vec{n} \\
\vec{n}\end{array}$ & & & & & & & & $\Re$ \\
\hline 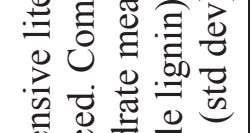 & हิ & $\vec{z}$ & & & & $\begin{array}{l}\text { a } \\
\text { in }\end{array}$ & $\begin{array}{l}a \\
e \\
\infty \\
\infty \\
\infty \\
i\end{array}$ & & & & 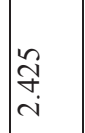 & & & & \\
\hline 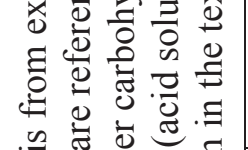 & 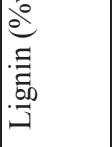 & 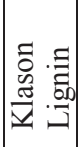 & $\frac{\sigma_{i}}{\dot{N}}$ & & & $\stackrel{n}{\tilde{\imath}}$ & 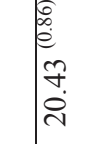 & $\frac{\hat{\imath}}{\dot{\lambda}}$ & م્ & 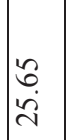 & $\mid \begin{array}{l}n \\
\infty \\
\infty \\
\vdots \\
\vdots\end{array}$ & ت্ं & & $\begin{array}{l}n \\
\stackrel{\infty}{\infty} \\
\infty \\
\varrho \\
-\end{array}$ & \\
\hline 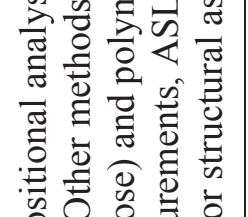 & & 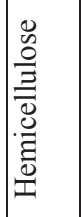 & & & & & & & 范 & & & & & 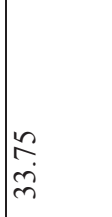 & 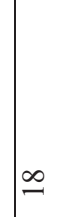 \\
\hline 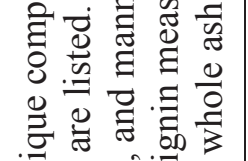 & & $\begin{array}{l}0 \\
0 \\
\frac{0}{3} \\
\overline{0} \\
0\end{array}$ & & & & & & & $\mid \begin{array}{l}n \\
0 \\
\infty \\
\dot{q} \\
\dot{q}\end{array}$ & & & & & 管 & q \\
\hline 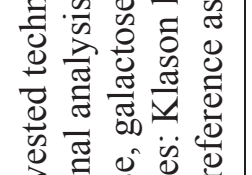 & & 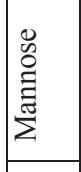 & సิ & $\exists$ & $\overline{0}$ & & & 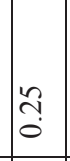 & & & & & & & \\
\hline 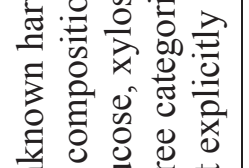 & & 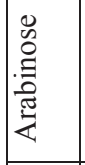 & 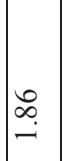 & $\stackrel{\vec{r}}{\sim}$ & 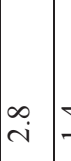 & 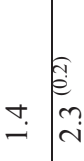 & & $\frac{n}{i}$ & & & $\stackrel{\Delta}{i}$ & & & & \\
\hline 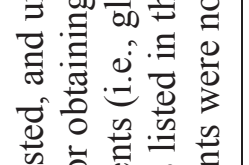 & & 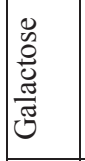 & : & $\stackrel{\vec{i}}{\stackrel{\Delta}{*}}$ & 吕 & 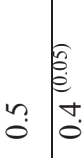 & & 常 & & & & & & & \\
\hline 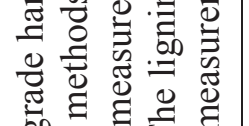 & 这 & $\frac{0}{0}$ & $\begin{array}{l}\infty \\
\infty \\
\stackrel{i}{i}\end{array}$ & 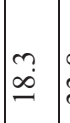 & $\stackrel{\infty}{m}$ & 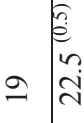 & 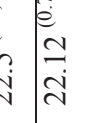 & 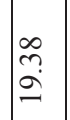 & & 角 & $\ddot{a}$ & 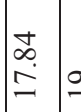 & 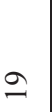 & & $\bar{N}$ \\
\hline 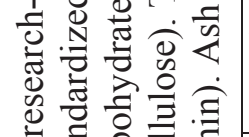 & 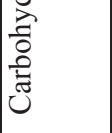 & $\begin{array}{l}0 \\
0 \\
0 \\
0 \\
0 \\
0\end{array}$ & \begin{tabular}{|l|}
$\vec{n}$ \\
$\qquad$ \\
$\dot{q}$ \\
\end{tabular} & 字 & 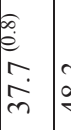 & 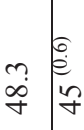 & 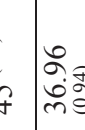 & $\vec{m}$ & & $\begin{array}{l}\tilde{r} \\
\tilde{\gamma}\end{array}$ & 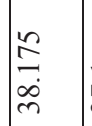 & & \& & & 寸 \\
\hline 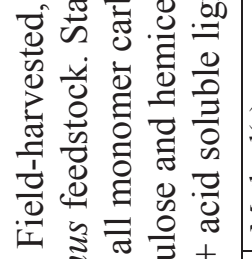 & 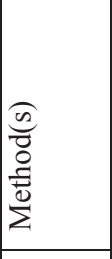 & & نم & 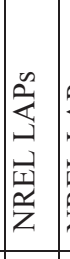 & 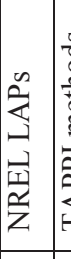 & 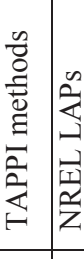 & 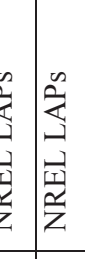 & & 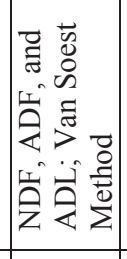 & 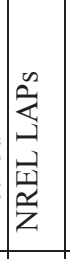 & 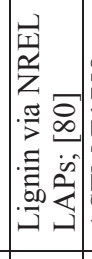 & 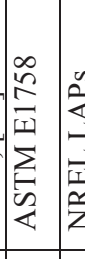 & 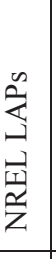 & 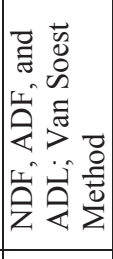 & : \\
\hline 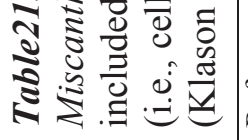 & 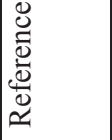 & & & : & 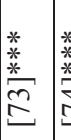 & 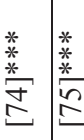 & 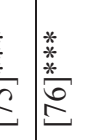 & 莣 & $\begin{array}{l}* \\
\infty \\
\infty\end{array}$ & $\frac{*}{2}$ & *\% & 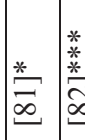 & 苂 & $\frac{*}{\infty}$ & 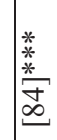 \\
\hline
\end{tabular}




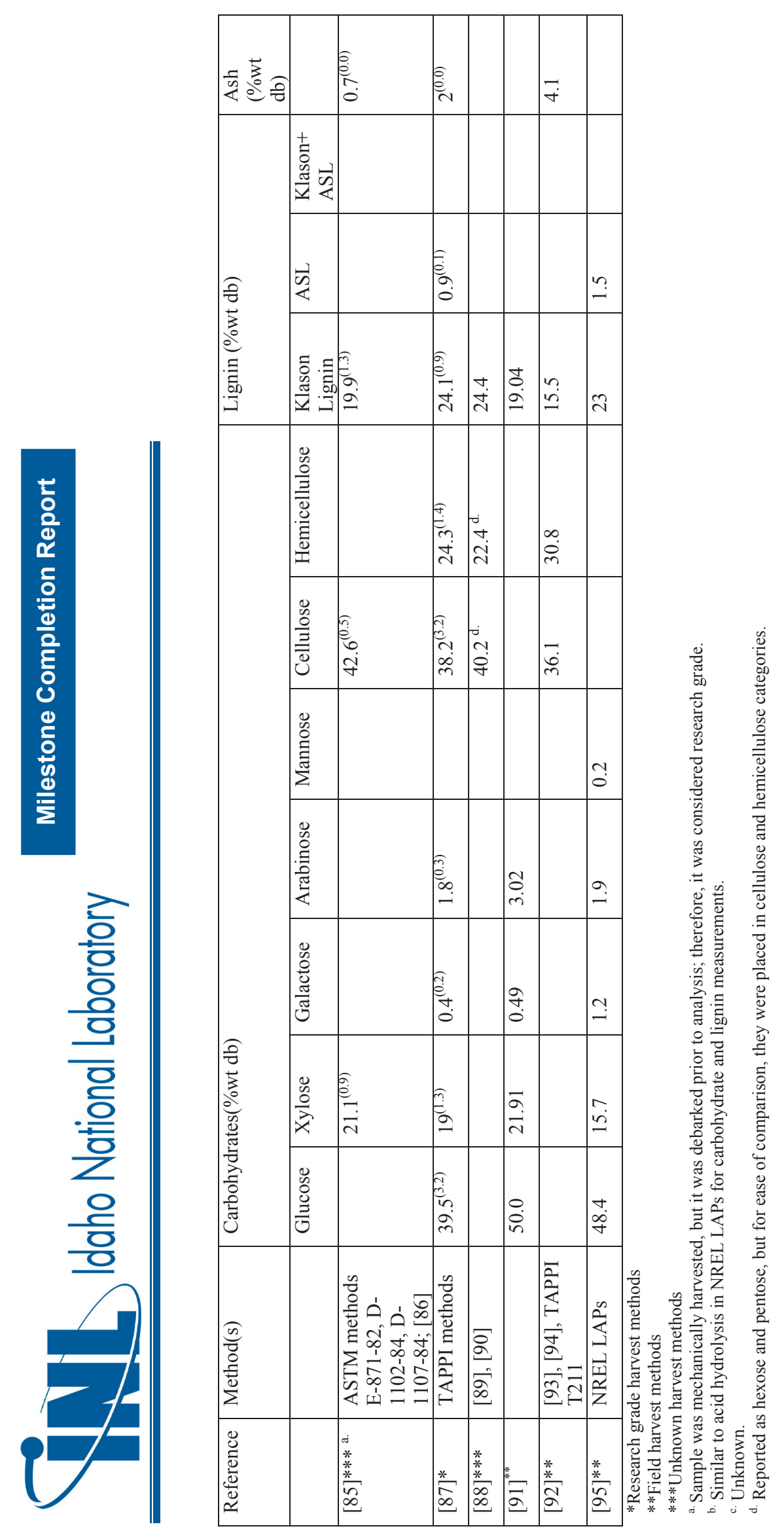

웅
$\stackrel{0}{0}$
ㅁ 


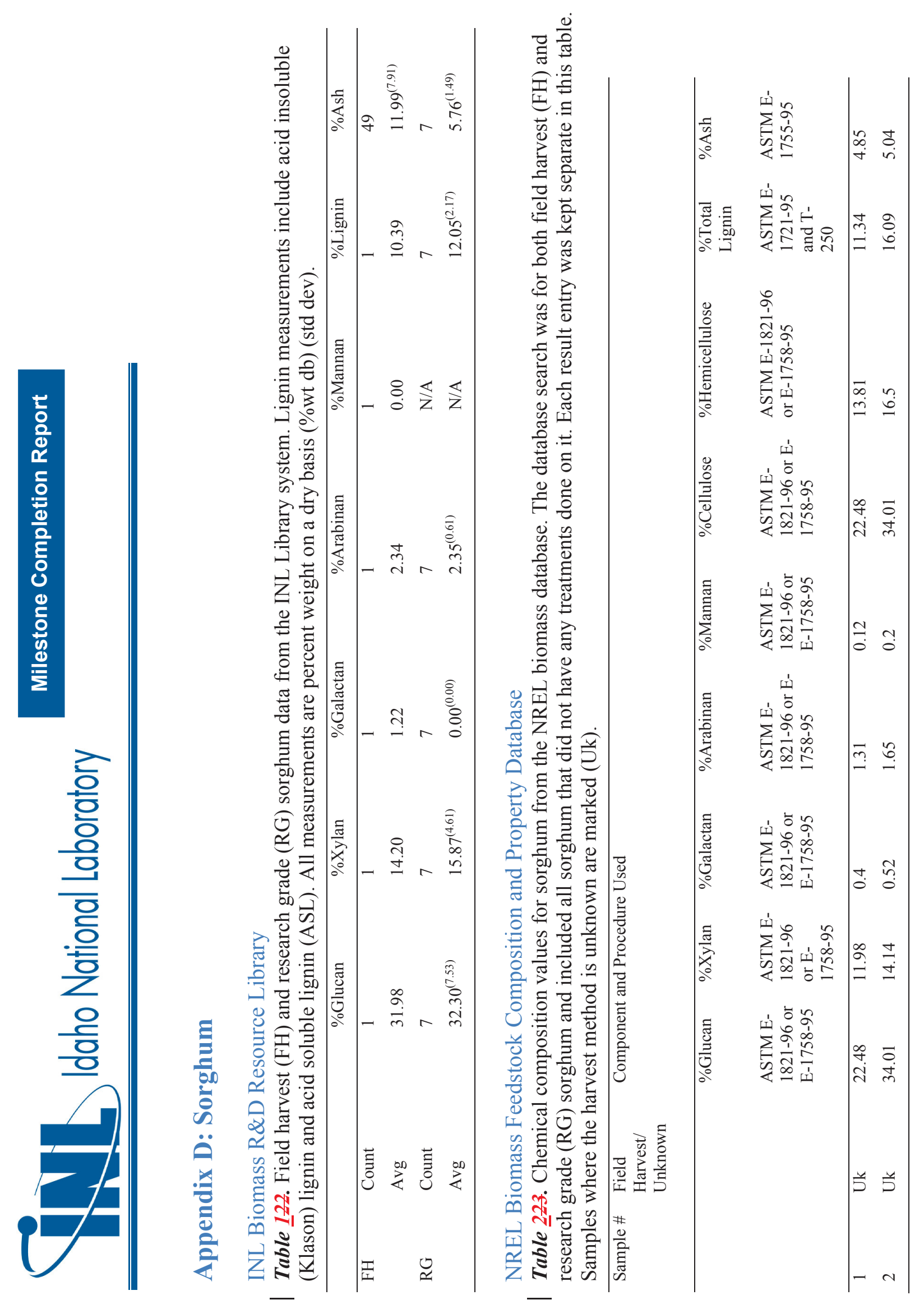

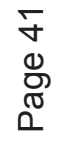



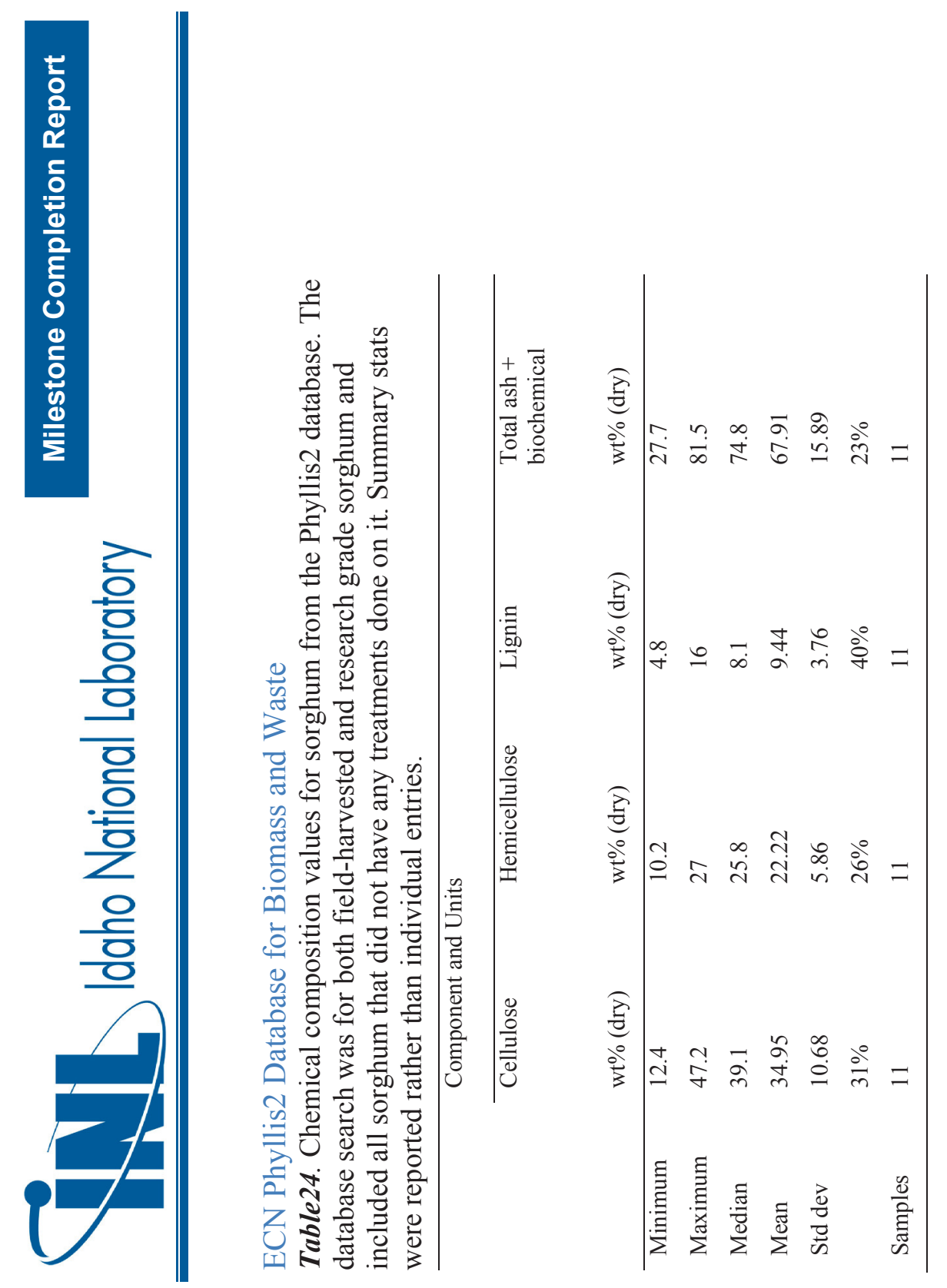


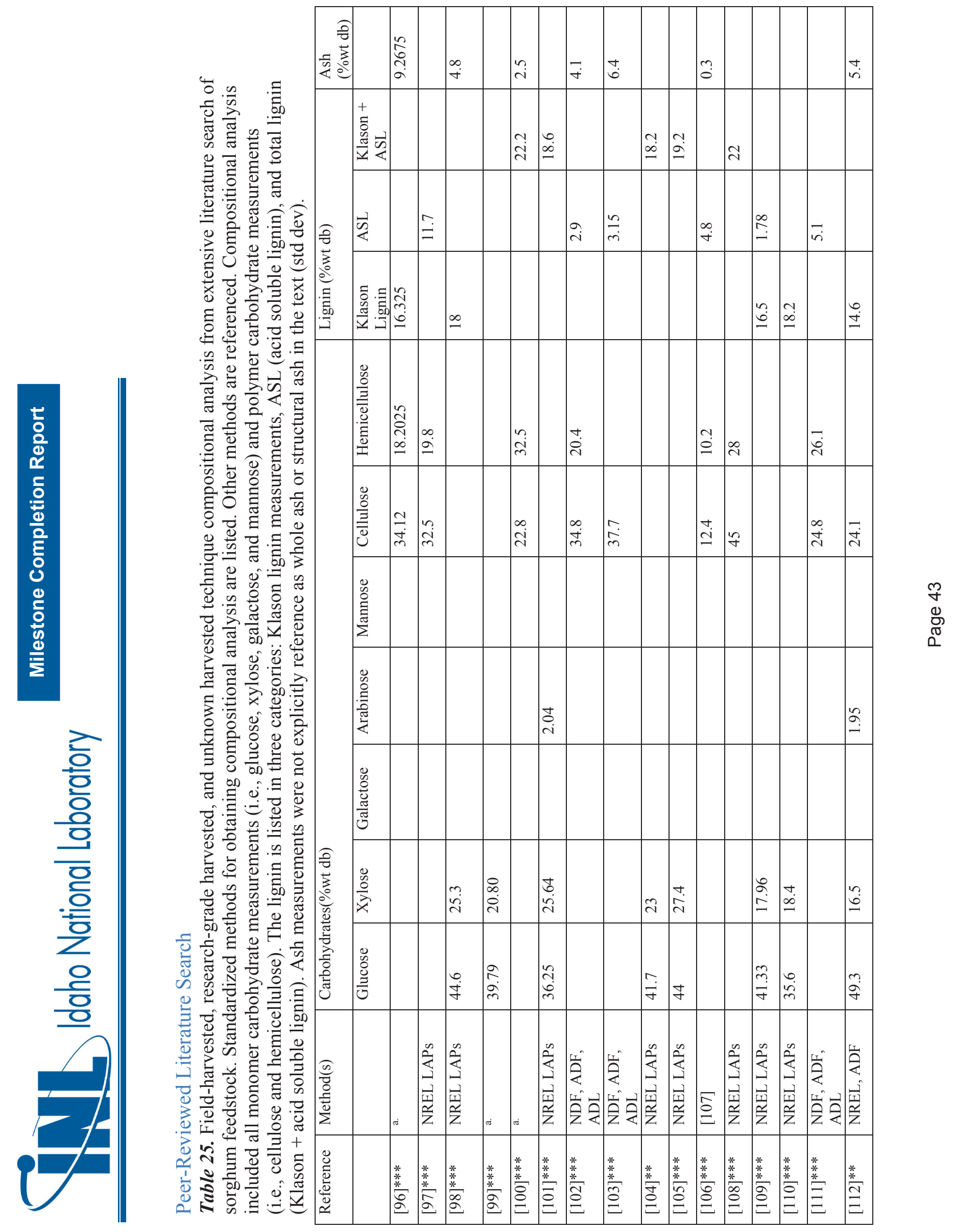




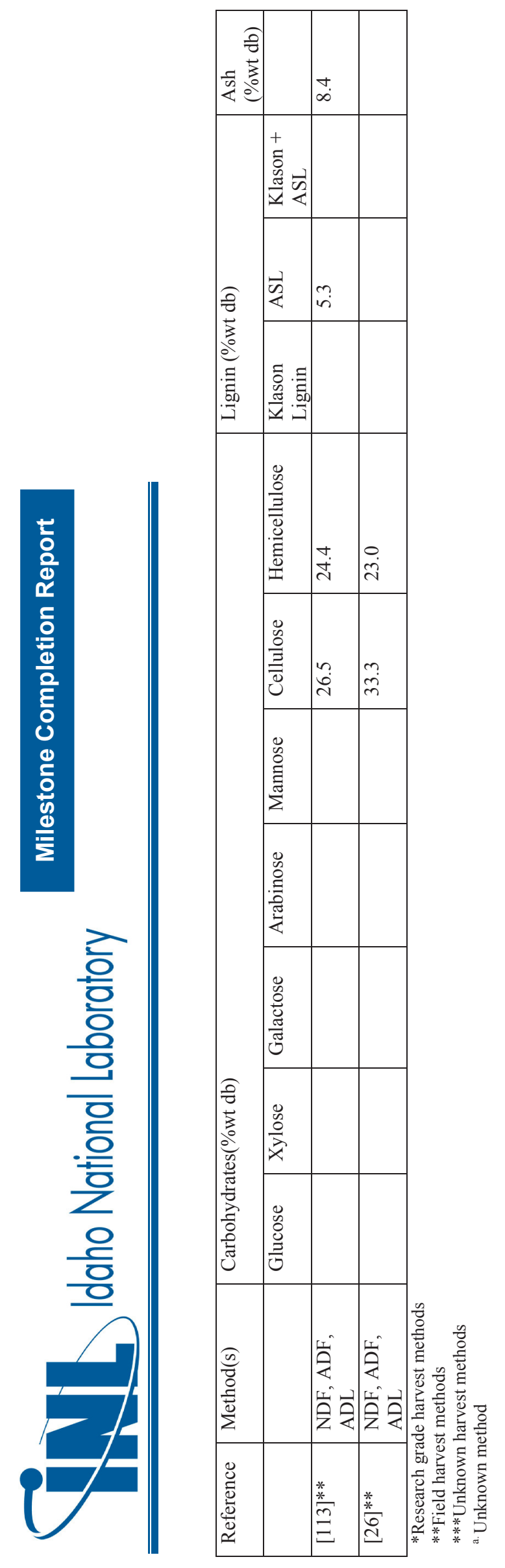

$\forall$
$\forall$
$\stackrel{0}{0}$
0 


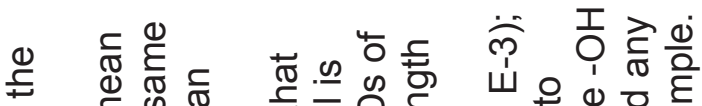

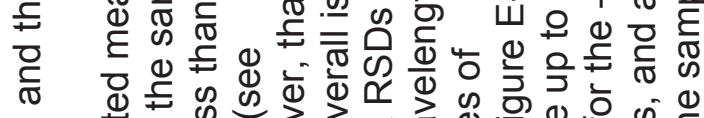

E

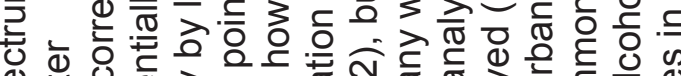

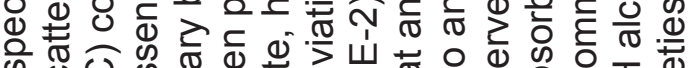

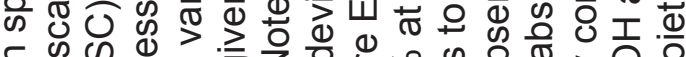

๙

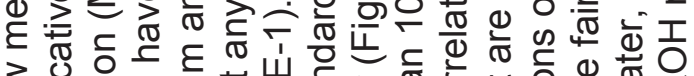

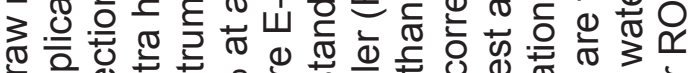

ญ
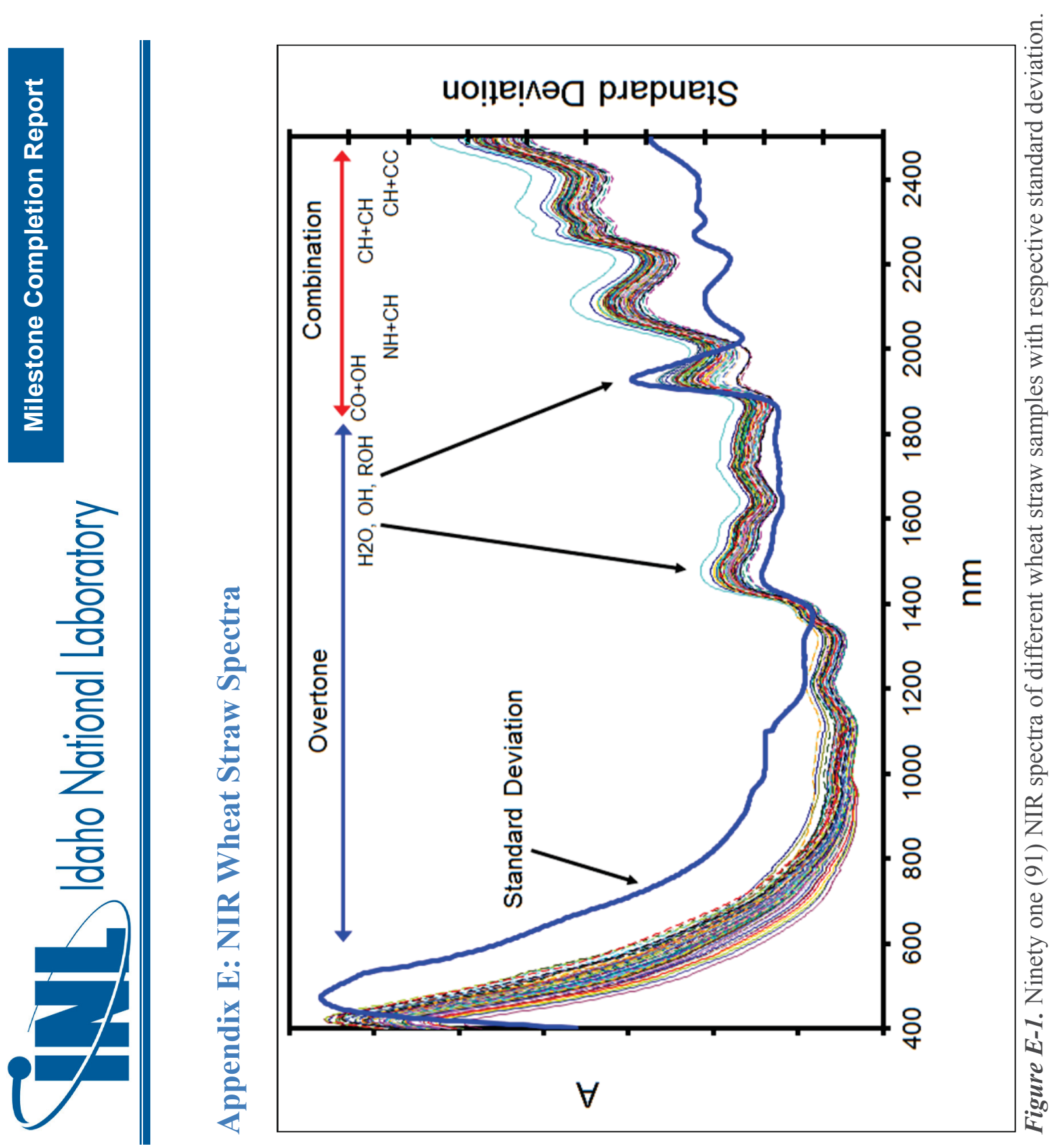


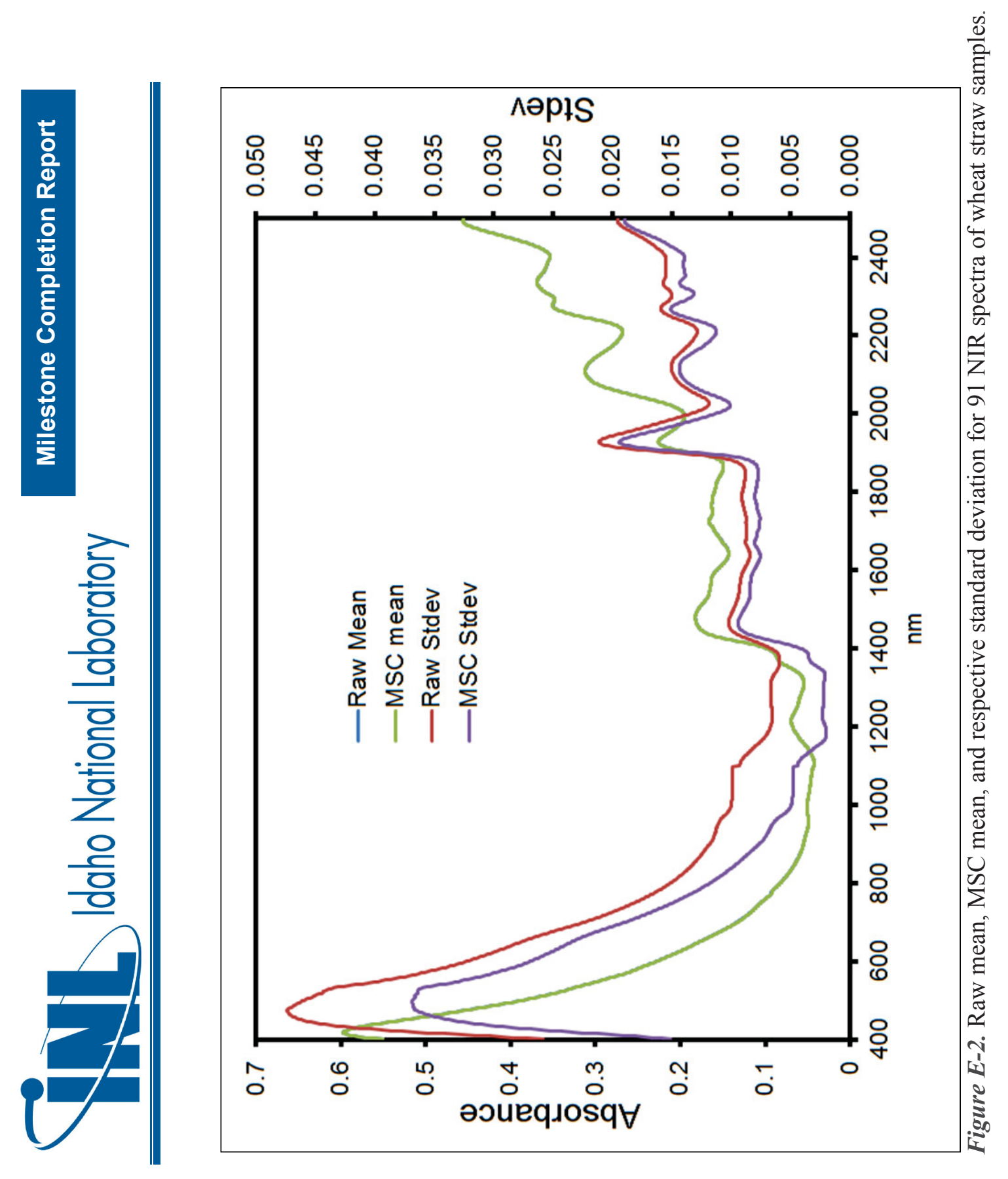

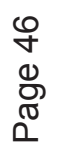




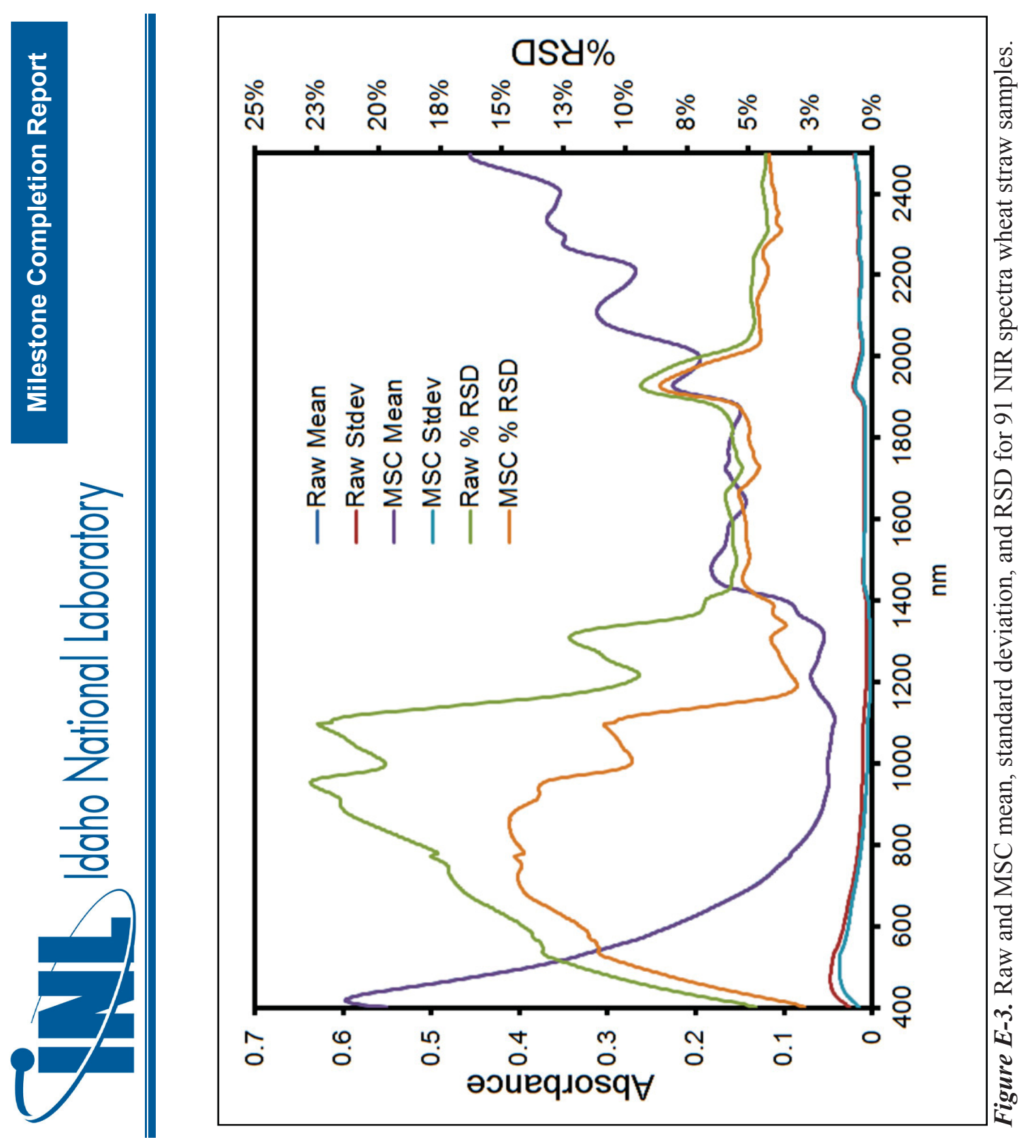

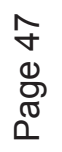




\section{References}

1. Lee, D., et al., Compostion of Herbaceous Biomass Feedstocks. 2007: Brookings, SD.

2. 7 CFR Part 810 - OFFICIAL UNITED STATES STANDARDS FOR GRAIN. 2011, Code of Federal Regulations: United States.

3. Official U.S. Standards for Wheat (Appendix 1 on page 26) and FGIS Grain Inspection Handbook II, Chapter 13, which can be found on the GIPSA Web site at http://archive.gipsa.usda.gov/reference-library/handbooks/grain-insp/grbook2/wheat.pdf..

4. 5. Shen, J. and J. Brodbelt, Dissociation of doubly charged transition metal/polyether/pyridyl ligand complexes in a quadrupole ion trap mass spectrometer. Journal of the American Society for Mass Spectrometry, 1999. 10(2): p. 126-135.

6. Simet, A., Preparation Protocol. Biomass Magazine, 2013: p. 14-19.

7. Bonner, I., et al., Impact of Collection Equipment on Ash Variability of Baled Corn Stover Biomass for Bioenergy. BioEnergy Research, 2013. in Progress.

8. Kenney, K.L., et al., Understanding biomass feedstock variabilit; special focus issue. Advanced Feedstocks for Advanced Biofuels, 2012. 4(1): p. 111-127.

9. Turn, S.Q., C.M. Kinoshita, and D.M. Ishimura, Removal of inorganic constituents of biomass feedstocks by mechanical dewatering and leaching. Biomass \& Bioenergy, 1997. 12(4): p. 241-252.

10. Humbird, D., et al., Process design and economics for biochemical conversion of lignocellulosic biomass to ethanol dilute-acid pretreatment and enzymatic hydrolysis of corn stover. 2011.

11. Templeton, D.W., et al., Compositional Analysis of Lignocellulosic Feedstocks. 2. Method Uncertainties. Journal of Agricultural and Food Chemistry, 2010. 58(16): p. 9054-9062.

12. Templeton, D.W., et al., Assessing corn stover composition and sources of variability via NIRS. Cellulose, 2009. 16(4): p. 621-639.

13. Hou, S. and L. Laigene, Rapid characterization of woody biomass digestibility and chemical composition using near-infrared spectroscopy. Journal of Integrative Plant Biology, 2011. 53(2): p. 166-175.

14. Gowen, A.A., et al., Hyperspectral imaging-an emerging process analytical tool for food quality and safety control. Trends in Food Science \& Technology, 2007. 18: p. 590-598.

15. Lachenmeier, D.W., Rapid quality control of spirit drinks and beer using multivariate data analysis of Fourier transform infrared spectra. Food Chemistry, 2007. 101: p. 825-832.

16. Blanco, M., et al., Quality control of cosmetic mixtures by NIR spectroscopy. Anal Bioanal Chem, 2007. 389: p. 1577-1583.

17. Luypaert, J., D.L. Massart, and Y.V. Heyden, Near-infrared spectroscopy applications in pharmaceutical analysis. Talanta, 2007. 72: p. 865-883.

18. Undersander, D., Uses and abuses of NIR for feed analysis. 2006, Florida Ruminant Nutrition Symposium.

19. Paakkunainen, M., J. Kohonen, and S.P. Reinikainen, Uncertainty and periodic behavior of process derived from online NIR. Analytica Chimica Acta, 2009. 642: p. 206-2011.

20. Barnes, R.J., M.S. Dhanoa, and S.J. Lister, Standard Normal Variate Transformation and Detrending of Near-Infrared Diffuse Reflectance Spectra. Applied Spectroscopy, 1989. 43(5): p. 5.

21. Wendt, L.M., et al., Influence of Airflow on Laboratory Storage of High Moisture Corn Stover. in Progress, 2013.

22. Idaho National Labratory, The 2017 Design Case - Feedstock Supply System Design and Economics for Conversion of Lignocellulosic Biomass to Hydrocarbon Fuels. 2013, in Progress. 
23. Wyman, C.E., et al., Comparative data on effects of leading pretreatments and enzyme loadings and formulations on sugar yields from different switchgrass sources. Bioresource technology, 2011. 102(24): p. 11052-11062.

24. Woodbury, P.B., Regional biomass feedstock partnership status report. 2011.

25. Liu, C., et al., Biomass properties from different Miscanthus species. Food and Energy Security, 2013. 2(1): p. 12-19.

26. Williams, S.D. and K.J. Shinners, Farm-scale anaerobic storage and aerobic stability of high dry matter sorghum as a biomass feedstock. Biomass and Bioenergy, 2012. 46(0): p. 309-316.

27. Shekiro, J., et al., Enzymatic Conversion of Xylan Residues from Dilute Acid-Pretreated Corn Stover. Applied biochemistry and biotechnology, 2012. 168(2): p. 421-433.

28. Garlock, R.J., et al., Influence of variable species composition on the saccharification of AFEX ${ }^{\mathrm{TM}}$ pretreated biomass from unmanaged fields in comparison to corn stover. Biomass and Bioenergy, 2012. 37(0): p. 49-59.

29. Zhu, J., C. Wan, and Y. Li, Enhanced solid-state anaerobic digestion of corn stover by alkaline pretreatment. Bioresource technology, 2010. 101(19): p. 7523-7528.

30. Li, X., T.H. Kim, and N.P. Nghiem, Bioethanol production from corn stover using aqueous ammonia pretreatment and two-phase simultaneous saccharification and fermentation (TPSSF). Bioresource technology, 2010. 101(15): p. 5910-5916.

31. Yoo, C.G., et al., Pretreatment of corn stover using low-moisture anhydrous ammonia (LMAA) process. Bioresource technology, 2011. 102(21): p. 10028-10034.

32. $\mathrm{Li}, \mathrm{X}$. and T.H. Kim, Low-liquid pretreatment of corn stover with aqueous ammonia. Bioresource technology, 2011. 102(7): p. 4779-4786.

33. Wan, C. and Y. Li, Microbial pretreatment of corn stover with Ceriporiopsis subvermispora for enzymatic hydrolysis and ethanol production. Bioresource technology, 2010. 101(16): p. 6398-6403.

34. Pang, F., et al., Effects of microwave power and microwave irradiation time on pretreatment efficiency and characteristics of corn stover using combination of steam explosion and microwave irradiation (SE-MI) pretreatment. Bioresource technology, 2012. 118(0): p. 111-119.

35. Yang, X., et al., Effect of biopretreatment on thermogravimetric and chemical characteristics of corn stover by different white-rot fungi. Bioresource technology, 2010. 101(14): p. 5475-5479.

36. Geng, X. and W.A. Henderson, Pretreatment of corn stover by combining ionic liquid dissolution with alkali extraction. Biotechnology and Bioengineering, 2012. 109(1): p. 84-91.

37. Shi, J., et al., Comparison of microwaves to fluidized sand baths for heating tubular reactors for hydrothermal and dilute acid batch pretreatment of corn stover. Bioresource technology, 2011. 102(10): p. 5952-5961.

38. Kaparaju, P. and C. Felby, Characterization of lignin during oxidative and hydrothermal pretreatment processes of wheat straw and corn stover. Bioresource technology, 2010. 101(9): p. 31753181.

39. Liu, Z.-H., et al., Evaluation of storage methods for the conversion of corn stover biomass to sugars based on steam explosion pretreatment. Bioresource technology, 2013. 132(0): p. 5-15.

40. Yue, Z., et al., Effects of dairy manure and corn stover co-digestion on anaerobic microbes and corresponding digestion performance. Bioresource technology, 2013. 128(0): p. 65-71.

41. Yoo, C.G., M. Kuo, and T.H. Kim, Ethanol and furfural production from corn stover using a hybrid fractionation process with zinc chloride and simultaneous saccharification and fermentation (SSF). Process Biochemistry, 2012. 47(2): p. 319-326. 
42. Qin, L., et al., High temperature aqueous ammonia pretreatment and post-washing enhance the high solids enzymatic hydrolysis of corn stover. Bioresource technology, 2013. 146(0): p. 504-511.

43. Chen, X., et al., Comparison of different mechanical refining technologies on the enzymatic digestibility of low severity acid pretreated corn stover. Bioresource technology, 2013. 147(0): p. 401-408.

44. Hongzhang, C., L. Hongqiang, and L. Liying, The inhomogeneity of corn stover and its effects on bioconversion. Biomass and Bioenergy, 2011. 35(5): p. 1940-1945.

45. Chen, X., et al., Improved Xylan Hydrolysis of Corn Stover by Deacetylation with High Solids Dilute Acid Pretreatment. Industrial \& Engineering Chemistry Research, 2011. 51(1): p. 70-76.

46. D. Humbird, R.D., L. Tao, C. Kinchin, D. Hsu, and A. Aden, P. Schoen, J. Lukas, B. Olthof, M. Worley, D. Sexton, and D. Dudgeon, Process design and economics for biochemical conversion of lignocellulosic biomass to ethanol: Dilute-Acid Pretreatment and Enzymatic Hydrolysis of Corn Stover, in Technical Report. 2011, NREL: Golden. p. 275-3000.

47. Templeton, D., et al., Assessing corn stover composition and sources of variability via NIRS. Cellulose, 2009. 16(4): p. 621-639.

48. Weiss, N.D., J.D. Farmer, and D.J. Schell, Impact of corn stover composition on hemicellulose conversion during dilute acid pretreatment and enzymatic cellulose digestibility of the pretreated solids. Bioresource technology, 2010. 101(2): p. 674-678.

49. Dien, B.S., et al., Chemical composition and response to dilute-acid pretreatment and enzymatic saccharification of alfalfa, reed canarygrass, and switchgrass. Biomass and Bioenergy, 2006. 30(10): p. 880-891.

50. Smith, D., The nonstructural carbohydrates. Chemistry and biochemistry of herbage,, ed. Bailey and RW. Vol. 1. 1973, New York: NY: Academic Press.

51. Li, C., et al., Comparison of dilute acid and ionic liquid pretreatment of switchgrass: Biomass recalcitrance, delignification and enzymatic saccharification. Bioresource technology, 2010. 101(13): p. 4900-4906.

52. Faga, B.A., M.R. Wilkins, and I.M. Banat, Ethanol production through simultaneous saccharification and fermentation of switchgrass using Saccharomyces cerevisiae D5A and thermotolerant Kluyveromyces marxianus IMB strains. Bioresource technology, 2010. 101(7): p. 2273-2279.

53. Suryawati, L., et al., Simultaneous saccharification and fermentation of Kanlow switchgrass pretreated by hydrothermolysis using Kluyveromyces marxianus IMB4. Biotechnology and Bioengineering, 2008. 101(5): p. 894-902.

54. Yat, S.C., A. Berger, and D.R. Shonnard, Kinetic characterization for dilute sulfuric acid hydrolysis of timber varieties and switchgrass. Bioresource technology, 2008. 99(9): p. 3855-3863.

55. Xu, J., et al., Sodium Hydroxide Pretreatment of Switchgrass for Ethanol Production. Energy \& Fuels, 2010. 24(3): p. 2113-2119.

56. Gupta, R. and Y.Y. Lee, Investigation of biomass degradation mechanism in pretreatment of switchgrass by aqueous ammonia and sodium hydroxide. Bioresource technology, 2010. 101(21): p. 8185-8191.

57. Mulkey, V.R., V.N. Owens, and D.K. Lee, Management of Switchgrass-Dominated Conservation Reserve Program Lands for Biomass Production in South Dakota This research was funded in part by the South Dakota Agric. Exp. Stn., the U.S. Dep. of Energy through contract DE-FC3602G012028, A000 with the Great Plains Institute for Sustainable Development, Minneapolis, MN, and the U.S. Dep. of Energy through contract DE-A105-900R2194 with Oak Ridge National 
Laboratory (ORNL). ORNL is managed by UT-Battelle, LLC, for the U.S. Dep. of Energy under contract DE-AC05-00OR22725. South Dakota Agric. Exp. Stn. Journal Series No. 3490. Crop Sci., 2006. 46(2): p. 712-720.

58. Bals B, R.C., Jin M, Balan V, Dale B., Evaluation of ammonia fibre expansion (AFEX) pretreatment for enzymatic hydrolysis of switchgrass harvested in different seasons and locations. Biotechnol Biofuels, 2010. 3(1): p. 1.

59. He, R., et al., Influence of pyrolysis condition on switchgrass bio-oil yield and physicochemical properties. Bioresource technology, 2009. 100(21): p. 5305-5311.

60. Vogel, K., et al., Quantifying Actual and Theoretical Ethanol Yields for Switchgrass Strains Using NIRS Analyses. BioEnergy Research, 2011. 4(2): p. 96-110.

61. Theander O, A.P., Westerlund E, Andersson R, Pettersson D., Total dietary fiber determined as neutral sugar residues, uronic acid residues, and Klason lignin (the Uppsala method): collaborative study. J AOAC Int., 1995. 78(4): p. 1030-44.

62. Liu, L., et al., Variability of biomass chemical composition and rapid analysis using FT-NIR techniques. Carbohydrate Polymers, 2010. 81(4): p. 820-829.

63. Nlewem, K.C. and M.E. Thrash Jr, Comparison of different pretreatment methods based on residual lignin effect on the enzymatic hydrolysis of switchgrass. Bioresource technology, 2010. 101(14): p. 5426-5430.

64. Kumar, S., et al., Hydrothermal pretreatment of switchgrass and corn stover for production of ethanol and carbon microspheres. Biomass and Bioenergy, 2011. 35(2): p. 956-968.

65. Karunanithy, C. and K. Muthukumarappan, Effect of Extruder Parameters and Moisture Content of Switchgrass, Prairie Cord Grass on Sugar Recovery from Enzymatic Hydrolysis. Applied biochemistry and biotechnology, 2010. 162(6): p. 1785-1803.

66. Ewanick, S. and R. Bura, The effect of biomass moisture content on bioethanol yields from steam pretreated switchgrass and sugarcane bagasse. Bioresource technology, 2011. 102(3): p. 26512658.

67. Sladden, S.E., D.I. Bransby, and G.E. Aiken, Biomass yield, composition and production costs for eight switchgrass varieties in Alabama. Biomass and Bioenergy, 1991. 1(2): p. 119-122.

68. Lemus, R., et al., Biomass yield and quality of 20 switchgrass populations in southern Iowa, USA. Biomass and Bioenergy, 2002. 23(6): p. 433-442.

69. Wiselogel, A.E., et al., Compositional changes during storage of large round switchgrass bales. Bioresource technology, 1996. 56(1): p. 103-109.

70. Adler, P.R., et al., Biomass Yield and Biofuel Quality of Switchgrass Harvested in Fall or Spring Mention of trade names or commercial products in this publication is solely for the purpose of providing specific information and does not imply recommendation or endorsement by the USDA. Agron. J., 2006. 98(6): p. 1518-1525.

71. Butler, E., et al., Characterisation of spruce, salix, miscanthus and wheat straw for pyrolysis applications. Bioresource technology, 2013. 131(0): p. 202-209.

72. Brandt, A., et al., Ionic liquid pretreatment of lignocellulosic biomass with ionic liquid-water mixtures. Green Chemistry, 2011. 13(9): p. 2489-2499.

73. Brosse, N., P. Sannigrahi, and A. Ragauskas, Pretreatment of Miscanthus x giganteus Using the Ethanol Organosolv Process for Ethanol Production. Industrial \& Engineering Chemistry Research, 2009. 48(18): p. 8328-8334. 
74. Faix, O., D. Meier, and O. Beinhoff, Analysis of lignocelluloses and lignins from Arundo donax L. and Miscanthus sinensis Anderss., and hydroliquefaction of Miscanthus. Biomass, 1989. 18(2): p. 109-126.

75. El Hage, R., et al., Effect of autohydrolysis of Miscanthus $x$ giganteus on lignin structure and organosolv delignification. Bioresource technology, 2010. 101(23): p. 9321-9329.

76. Minhee Han, Y.K., Bon-cheol Koo, Gi-Wook Choi, Bioethanol Production by Miscanthus as a Lignocellulosic Biomass: Focus on High Efficiency Conversion to Glucose and Ethanol. BioResources, 2011. 6(2): p. 1939-1953.

77. Haverty, D., et al., Autothermal, single-stage, performic acid pretreatment of Miscanthus $x$ giganteus for the rapid fractionation of its biomass components into a lignin/hemicellulose-rich liquor and a cellulase-digestible pulp. Bioresource technology, 2012. 109(0): p. 173-177.

78. Hodgson, E.M., et al., Variation in Miscanthus chemical composition and implications for conversion by pyrolysis and thermo-chemical bio-refining for fuels and chemicals. Bioresource technology, 2011. 102(3): p. 3411-3418.

79. Hong, C., et al., Comparative Growth, Biomass Production and Fuel Properties Among Different Perennial Plants, Bamboo and Miscanthus. The Botanical Review, 2011. 77(3): p. 197-207.

80. Sjostrom, E., and R. Alen, Analytical methods in wood chemistry, pulping, and papermaking. Springer Series in Wood Science. 1999: Verlag.

81. Melligan, F., et al., Characterisation of the products from pyrolysis of residues after acid hydrolysis of Miscanthus. Bioresource technology, 2012. 108(0): p. 258-263.

82. Murnen, H.K., et al., Optimization of Ammonia Fiber Expansion (AFEX) Pretreatment and Enzymatic Hydrolysis of Miscanthus x giganteus to Fermentable Sugars. Biotechnology Progress, 2007. 23(4): p. 846-850.

83. Jingping Qin, Y.Y., Jianxiong Jiang, Zili Yi*, Liang Xiao, Xin Ai and Zhiyong Chen, Comparison of lignocellulose composition in four major species of Miscanthus. African Journal of Biotechnology, 2012. 11(62): p. 12529-12537.

84. Sørensen, A., et al., Hydrolysis of Miscanthus for bioethanol production using dilute acid presoaking combined with wet explosion pre-treatment and enzymatic treatment. Bioresource technology, 2008. 99(14): p. 6602-6607.

85. Velásquez, J.A., F. Ferrando, and J. Salvadó, Binderless fiberboard from steam exploded Miscanthus sinensis: The effect of a grinding process. Holz als Roh- und Werkstoff, 2002. 60(4): p. 297-302.

86. Yuan, J.P. and F. Chen, Simultaneous separation and determination of sugars, ascorbic acid and furanic compounds by HPLC — dual detection. Food Chemistry, 1999. 64(3): p. 423-427.

87. de Vrije, T., et al., Pretreatment of Miscanthus for hydrogen production by Thermotoga elfii. International Journal of Hydrogen Energy, 2002. 27(11-12): p. 1381-1390.

88. Yoshida, M., et al., Effects of Cellulose Crystallinity, Hemicellulose, and Lignin on the Enzymatic Hydrolysis of Miscanthus sinensis to Monosaccharides. Bioscience, Biotechnology, and Biochemistry, 2008. 72(3): p. 805-810.

89. Morris, D.L., Quantitative Determination of Carbohydrates With Dreywood's Anthrone Reagent. Science, 1948. 5(March): p. 254-255.

90. Mejbaum, W., U ber die Bestimmung kleiner Pentosemengen, insbesondere in Derivaten der Adenylsa ure. Z. Physiol. Chem., 1939. 285: p. 117-120.

91. Huyen, T.L.N, C.Remond, R. M. Dheilly, B. Chabbert, Effect of harvesting date on the composition and saccharification of Miscanthus $x$ giganteus. Bioresource technology, 2010. 101(21): p. 82248231. 
92. Serrano, L., et al., Miscanthus sinensis fractionation by different reagents. Chemical Engineering Journal, 2010. 156(1): p. 49-55.

93. L.E. Wise, M.M., A. D'Adieco, Chlorite holocellulose, its fractionation and bearing on summative wood analysis and on studies on the hemicelluloses. Paper Trade Journal, 1946. 122(2): p. 35-43.

94. Rowell, R., The chemistry of solid wood: based on short course and symposium sponsored by the division of cellulose, paper, and textile chemistry at the 185th meeting of the American Chemical Society, in 185th meeting of the American Chemical Society. 1983: Seattle, Washington. p. 70-72.

95. Vanderghem, C., et al., Optimization of formic/acetic acid delignification of Miscanthus ×giganteus for enzymatic hydrolysis using response surface methodology. Industrial Crops and Products, 2012. 35(1): p. 280-286.

96. Corredor, D.Y., et al., Evaluation and Characterization of Forage Sorghum as Feedstock for Fermentable Sugar Production. Applied biochemistry and biotechnology, 2009. 158(1): p. 164-179.

97. Xu, F., et al., Sulfuric acid pretreatment and enzymatic hydrolysis of photoperiod sensitive sorghum for ethanol production. Bioprocess and Biosystems Engineering, 2011. 34(4): p. 485-492.

98. Ballesteros, M., et al., Ethanol from lignocellulosic materials by a simultaneous saccharification and fermentation process (SFS) with Kluyveromyces marxianus CECT 10875. Process Biochemistry, 2004. 39(12): p. 1843-1848.

99. Wang, W., et al., High consistency enzymatic saccharification of sweet sorghum bagasse pretreated with liquid hot water. Bioresource technology, 2012. 108(0): p. 252-257.

100. Yu, J., et al., Biorefinery of sweet sorghum stem. Biotechnology Advances, 2012. 30(4): p. 811-816.

101. Sipos, B., et al., Sweet Sorghum as Feedstock for Ethanol Production: Enzymatic Hydrolysis of Steam-Pretreated Bagasse. Applied biochemistry and biotechnology, 2009. 153(1-3): p. 151-162.

102. Sattler, S.E., D.L. Funnell-Harris, and J.F. Pedersen, Brown midrib mutations and their importance to the utilization of maize, sorghum, and pearl millet lignocellulosic tissues. Plant Science, 2010. 178(3): p. 229-238.

103. Gunaseelan, V.N., Regression models of ultimate methane yields of fruits and vegetable solid wastes, sorghum and napiergrass on chemical composition. Bioresource technology, 2007. 98(6): p. 12701277.

104. Theerarattananoon, K., et al., Effects of the pelleting conditions on chemical composition and sugar yield of corn stover, big bluestem, wheat straw, and sorghum stalk pellets. Bioprocess and Biosystems Engineering, 2012. 35(4): p. 615-623.

105. Yu, Y., X. Lou, and H. Wu, Some Recent Advances in Hydrolysis of Biomass in Hot-Compressed Water and Its Comparisons with Other Hydrolysis Methods $\%$ Energy \& Fuels, 2007. 22(1): p. 46-60.

106. Billa, E., et al., Structure and composition of sweet sorghum stalk components. Industrial Crops and Products, 1997. 6(3-4): p. 297-302.

107. Saeman, J.F., J.L. Bubl, and E.E. Harris, Quantitative Saccharification of Wood and Cellulose. Industrial \& Engineering Chemistry Analytical Edition, 1945. 17(1): p. 35-37.

108. Salvi, D.A., et al., Ethanol production from sorghum by a dilute ammonia pretreatment. Journal of Industrial Microbiology \& Biotechnology, 2010. 37(1): p. 27-34.

109. Goshadrou, A., K. Karimi, and M.J. Taherzadeh, Bioethanol production from sweet sorghum bagasse by Mucor hiemalis. Industrial Crops and Products, 2011. 34(1): p. 1219-1225.

110. Li, B.-Z., et al., Process optimization to convert forage and sweet sorghum bagasse to ethanol based on ammonia fiber expansion (AFEX) pretreatment. Bioresource technology, 2010. 101(4): p. 12851292. 


\section{Milestone Completion Report}

111. Miron, J., et al., Yield, composition and in vitro digestibility of new forage sorghum varieties and their ensilage characteristics. Animal Feed Science and Technology, 2005. 120(1-2): p. 17-32.

112. Dien, B., et al., Improved Sugar Conversion and Ethanol Yield for Forage Sorghum (Sorghum bicolor L. Moench) Lines with Reduced Lignin Contents. BioEnergy Research, 2009. 2(3): p. 153164.

113. Miron, J., et al., Field yield, ensiling properties and digestibility by sheep of silages from two forage sorghum varieties. Animal Feed Science and Technology, 2007. 136(3-4): p. 203-215. 